IZA DP No. 7825

The US Labor Market in 2030: A Scenario

Based on Current Trends in Supply and Demand

Rebecca Edwards

Fabian Lange

December 2013 


\title{
The US Labor Market in 2030: A Scenario Based on Current Trends in Supply and Demand
}

\author{
Rebecca Edwards \\ University of Sydney \\ Fabian Lange \\ McGill University \\ and IZA
}

\section{Discussion Paper No. 7825 \\ December 2013}

\author{
IZA \\ P.O. Box 7240 \\ 53072 Bonn \\ Germany \\ Phone: +49-228-3894-0 \\ Fax: +49-228-3894-180 \\ E-mail: iza@iza.org
}

\begin{abstract}
Any opinions expressed here are those of the author(s) and not those of IZA. Research published in this series may include views on policy, but the institute itself takes no institutional policy positions. The IZA research network is committed to the IZA Guiding Principles of Research Integrity.

The Institute for the Study of Labor (IZA) in Bonn is a local and virtual international research center and a place of communication between science, politics and business. IZA is an independent nonprofit organization supported by Deutsche Post Foundation. The center is associated with the University of Bonn and offers a stimulating research environment through its international network, workshops and conferences, data service, project support, research visits and doctoral program. IZA engages in (i) original and internationally competitive research in all fields of labor economics, (ii) development of policy concepts, and (iii) dissemination of research results and concepts to the interested public.
\end{abstract}

IZA Discussion Papers often represent preliminary work and are circulated to encourage discussion. Citation of such a paper should account for its provisional character. A revised version may be available directly from the author. 
IZA Discussion Paper No. 7825

December 2013

\section{ABSTRACT \\ The US Labor Market in 2030: \\ A Scenario Based on Current Trends in Supply and Demand}

Three fundamental forces have shaped labor markets over the last 50 years: the secular increase in the returns to education, educational upgrading, and the integration of large numbers of women into the workforce. We modify the Katz and Murphy (1992) framework to predict the structure of the labor market in 2030. Even though the share of educated females in the workforce will grow rapidly, the supply response will not suffice to offset the trend in demand towards skilled, female labor. Wage growth over the next 20 years will continue to favor college educated workers and in particular college educated females.

JEL Classification: J11, J21, J22, J23, J31

Keywords: $\quad$ wage growth, trends in labor demand and supply

Corresponding author:

Fabian Lange

Department of Economics

McGill University

Leacock Building Room 443

855 Sherbrooke Street

West Montreal, Quebec, H3A 2T7

Canada

E-mail: fabian.lange@mcgill.ca

\footnotetext{
* We thank seminar participants at the Economics departments at the University of Sydney and the University of NSW for their helpful comments.
} 
Three fundamental forces have shaped US labor markets over the last 50 years: a secular increase in the returns to education, general education upgrading, and the integration of large numbers of women into the workforce. In this paper, we adapt the Katz and Murphy (1992) (hereafter KM) framework to account for these fundamental driving forces over the last halfcentury. We then use this model together with a model of labor supply and projections of how educational attainment, demographics, and human capital endowments will evolve in the future to predict how the male-female wage gap and the returns to education and gender will evolve over the next 20 years.

There are four main reasons why we believe such an exercise is useful. First, the social returns to education policies today depend on the relative prices that labor of different education levels will command in the labor market 20 years from now. Second, current labor market trends appear to leave a large group behind: less educated males. The rationale for social policies targeted specifically to this population is strengthened if predicted future outcomes in labor markets will lead this group to fall even further behind. Third, in order to arrive at our predictions, we examine the KM framework in detail and adapt it to account for (i) changes in endowments of human capital conditional on skill, and (ii) endogenous labor supply. Fourth, the ultimate success of the KM model derives from its ability to predict future labor market outcomes. By providing an out-of-sample prediction of future labor market trends based on this model, we provide a baseline prediction to evaluate the performance of the model over future decades.

We base our analysis on the Current Population Surveys (CPS) from 1963-2011. We begin by decomposing the overall changes in labor supplied at a given education level into three components: changes in the size of the working age population, changes in hours worked conditional on being of working age, and changes in the skills (effective human capital units) embodied in workers of different education levels, gender, and age. Over the last half-century, the labor supplied by both highly educated men and women increased substantially relative to the supply of labor by the less educated. Among men, this is largely due to an increase in educational attainment; highly educated men did not differentially increase their hours supplied compared to less educated men, nor did they experience differential increases in their human capital endowments. For women, we find large increases in the labor supplied by working age women that are due to both large increases in hours worked and increases in educational attainment.

We obtain parsimonious production function estimates that allow us project the demand for male and female workers of different education levels. These estimates are based on two 
different sets of assumptions. A first set of estimates follows the literature and restricts the supply of hours to be exogenous to wages. A second set of estimates endogenizes the supply of hours. To identify the model with endogenous labor supply, we use changes in the demographic and education structure of the population to generate variation in the supply of labor that is exogenous to demand shifts. This variation derives from educational upgrading across cohorts and from the demographic variation induced by the baby-boom and bust.

We modify the KM framework by relaxing the assumption that male and female workers are perfect substitutes in production. This modification is necessary to account for the significant narrowing of the male-female wage gap between 1963 and 2011 and the concurrent substantial increase in the share of females in the work-force.

Our estimates show long-run declines in the demand for male relative to female labor. We also find, as does much of the literature, a long-run demand trend towards more highly educated workers. The estimates indicate shifts of labor demand of 0.8 percent annually in favor of female relative to male labor and also in favor of college relative to high school type labor. The estimated elasticities of substitution between male and female labor are fairly high, ranging between about 1.7 and 5.3, depending on the specification. Our estimated elasticities of substitution between high school and college educated labor range between 3.0 and 6.5 .

To predict the wage structure in 2030 we combine our specification of labor demand with projected changes in labor supply. We predict future labor supply using: (i) projected population growth rates from the Census Bureau along with extrapolations of trends in educational attainment, (ii) predicted hours supplied using a labor supply elasticity drawn from the literature, and (iii) projected trends in the skills of the working age population with each level of education using directly measured skills for older cohorts and extrapolations for younger cohorts. Our predictions suggest that over the next 20 years the growth in human capital rental rates will continue to favor college educated workers and in particular college educated females. The labor supply response to these higher returns for college workers does serve to attenuate the increase in inequality. Nevertheless, if demand for educated and female labor continues to grow at the rates we experienced over the last 50 years, then the rental rate for female college labor will appreciate by 0.8 percent per annum relative to college educated males and by about 1.3 percent per annum relative to high school educated males. 


\section{Measuring Rental Rates and Quantities of Human Cap- ital}

Observed wages confound the rental rates for human capital services with the amounts of human capital supplied to the market. The problem is to separately identify time-series of the rental rates of human capital and the endowments of human capital by workers from wage data alone. That is, the wage offer $W_{i, t}$ for an individual $i$ in year $t$ is the product of the rental rate $R_{t}$ and the quantity of human capital supplied $Q_{i, t}$ by that individual: $W_{i . t}=R_{t} Q_{i, t}$.

To resolve this identification problem, we must make structural assumptions that allow us to compare similar units over time. The traditional approach, following KM and more recently Autor, Katz and Kearney (2008), is to assume that the human capital endowments of individuals of similar experience, education, gender, and race do not change over time. This approach is sometimes referred to as the "standard unit approach", a terminology that we adopt below. Under the standard unit approach, wages of individuals with fixed characteristics change only if the rental rates for the human capital supplied by these individuals change. Observed wages conditional on demographics thus trace out how rental rates evolve.

However, over the long run, this standard unit approach generates bias if the skills of workers conditional on experience, education, gender, and race change. One reason for such changes is that variation in rental rates for different types of skill can naturally be expected to induce endogenous responses in skill investments. For example, Heckman, Lochner and Taber (1998) find that on-the-job investment in skills responded to how the wage structure changed over the 1980s and 1990s. Skill endowments by education might also change because changes in the rental rates of human capital by education affect who selects into education. Carneiro and Lee (2011) argue that the selection by ability into college has changed substantially with the returns to education and Bowlus and Robinson (2012) argue that there have been technological improvements in human capital production functions. Each of these, selection into education, changing technology of human capital production and changing onthe-job investment behavior, invalidates the assumption that human capital conditional on experience and education is constant over the time. In addition, the standard unit approach will fail if the quality of schooling across and within demographic groups changes. Such change has for instance been observed for black versus white schooling (Card and Krueger (1992); Boozer, Krueger and Wolkon (1992)). Comparing the cohorts of the National Longitudinal Survey of Youth (NLSY) 1979 and NLSY 1997, Altonji, Bharadwaj and Lange 
(2012) provide direct evidence that average skill endowments conditional on race, education, experience, and gender have changed over the last few decades.

Heckman, Lochner and Taber (1998) propose an alternative approach to identify the rental rates of human capital that is motivated by the life-cycle model of human capital investments. The life-cycle model implies that individuals cease to invest into human capital as they approach retirement. At that point, earnings profiles for a given cohort will be flat unless rental rates change. Thus, changes in earnings within cohorts during these near-toretirement years identify changes in rental rates. This point in the life cycle is known as the "flat-spot". Bowlus and Robinson (2012) (BR hereafter) recently implement and refine this approach. They argue that the flat-spot should be identified across education using equivalent years of potential experience rather than using years of age, thus implying a flatspot for college educated workers that is later than the flat-spot for high school educated labor.

We implement this method (which we will term the flat-spot method) using data from the 1963-2011 CPS. That is, we compare wages within cohort, gender, and education group across years when individuals are at their flat-spot. We adopt the flat-spot ages as suggested by BR, namely ages 46-55 years for high-school educated labor and 50-59 years for college educated labor. Because the flat-spot method compares individual at ages long after they have completed schooling, this approach is robust to the issues of selectivity raised by Carneiro and Lee (2011) and to the possibility that schooling quality changes differentially across demographic groups and time. On the other hand, this approach requires that human capital across different experience levels are perfect substitutes (see Card and Lemieux (2001) for a contrasting perspective) and it requires that changes in labor force participation during the flat-spot periods are not systematically biasing comparisons across age within cohort.

Figures 1 and 2 compare the rental rates for men and women obtained using the standard unit approach with those obtained using the flat-spot approach. ${ }^{1}$ Each figure consists of four panels. The bottom left panel shows the rental rates obtained using individuals using the flat-spot method using the age ranges for high school and college type human capital recommended by BR. The top two panels show the rental rates obtained using the standard unit approach obtained using the entire age range 20-65 as well as using the BR ages. The bottom right panel then shows the relative rental rates for college and high school labor relative to the year 2011 that are obtained by log differencing the rental rates shown in the other three panels of these figures. All rental rates are shown relative to the year 2011.

\footnotetext{
${ }^{1}$ Appendix B describes the construction of the rental rates using the standard and flat-spot approaches.
} 
Even though the standard unit and the flat-spot methods rely on different assumptions, the rental rates obtained from both methods are quite similar. Regardless of method, we find the same pattern: the rental rates for college human capital relative to high school capital peak during the early 1970s, decline until about 1980 and increase over the 1980s and 1990s. The increase in the returns to college slows down during the early 2000s before it accelerates again during the last few years. Differences between the time-series arise almost entirely because of the age ranges on which they are estimated. That is, if we apply the standard unit approach and the flat-spot method to the same age groups (those recommended by $\mathrm{BR}$ ), we obtain time-series of rental rates that are very close to each other. This suggests that changes in selectivity into education are not of first order importance. However, the differences found using the standard unit approach on ages 20-65 compared to the BR ages suggest that changes in the endogenous accumulation of human capital during the first 20 years of careers have important effects on measured rentals rates and quantities (as pointed out by Heckman, Lochner and Taber (1998)). Thus, we think it wise to limit ourselves to the $\mathrm{BR}$ age groups. With this restriction in place, it is largely irrelevant whether one employs the standard unit or the flat-spot method to estimate the rental rates by skill-group. The analysis below is based on the flat-spot approach.

A comparison of Figures 1 and 2 reveals that males and females can not be treated as perfect substitutes with fixed relative productivity. Under the perfect substitutes assumption, the relative rental rates within education across gender would not vary over time. Clearly, Figures 1 and 2 contradict this: ${ }^{2}$ rental rates conditional on education evolve in different ways for men as opposed to women. For instance, the rental rates for female college graduates rise substantially faster than those for their male counterparts. Thus, we can not assume that relative productivity across gender did not change over our study period. Furthermore, the question of how to aggregate labor supply across gender is especially important since the increase in hours worked and labor force participation of women is probably the most important trend in labor markets during the 1963-2011 period. To accommodate these trends, we augment the framework by KM to account for changes in observed quantities and rental rates across education and gender within a setting of labor demand that is stable up to linear trends. It turns out that our approach is able to account for observed changes in the wage structure across education and gender groups over the last 50 years and we thus rely on it to project changes in the wage structure into the future. ${ }^{3}$

\footnotetext{
${ }^{2} \mathrm{KM}$ made this assumption, but during their study period (1963-1987) the workforce was more homogenous and this assumption therefore less problematic.

${ }^{3}$ Within gender, we attribute the human capital of "high school drop-outs" and 50 percent of those with
} 
We are unable to pursue a similar approach to account for how wages and employent of blacks and Hispanics changed relative to whites. Prior to 1980, too few blacks had college degrees to allow us to construct a precise time-series of rental rates for black college type labor. The same is true for Hispanics since migration into the US only took off during the 1980s and 1990s. It is therefore difficult to estimate labor demand parameters by race separately. Further, the decline in the black-white wage gap over the 1970s is difficult to reconcile with a simple demand and supply story, since black employment in this period increased substantially relative to that of whites while the wage-gap declined. Thus we did not succeed in describing the changes in relative wages and employment between blacks and whites using a simple supply and demand framework. As a result, we proceeded in two ways. Our first approach follows KM and subsequent authors in assuming that different ethnic groups within (but not across) education and gender are perfect substitutes with fixed weights over the 1963-2011 period. Our second approach is to drop all minorities from our data and estimate the labor demand and supply system using white males and females only. Our overall results are very similar, regardless of which approach we take. This reflects the fact that over the time-period considered here whites dominate the workforce. The results we present in this paper are based on whites and non-whites assuming they are perfect substitutes.

Our data come from the March CPS for 1963-1972 and from the May/Merged Outgoing Rotation Groups (MORG) surveys for 1973-2011.4 Once available, we use the May/MORG surveys because they collect hourly wages for hourly wage workers. As Lemieux (2006) discusses these measures are less likely to suffer from measurement error induced by division bias. Prior to 1973, the May/MORG data is not available and we rely on March CPS data for these years. In constructing our data, we followed Lemieux (2006) closely. Details of the sample selection and the construction of the variables are available in Appendix $B$ and the online appendix. Appendix B also details the construction of the flat-spot rental rates and the human capital quantities that individuals supply to the market.

\footnotetext{
"some college" to the high school-equivalent education or unskilled labor group assuming that these types of human capital are perfect substitutes. Similarly, we attribute the human capital of "post-graduate" and 50 percent of "some college" individuals to the skilled or college-equivalent labor group. Further details are provided in Appendix B.

${ }^{4}$ See Appendix A for details of the data sources.
} 


\section{Changes in Labor Supply}

In this Section, we describe the overall trends in effective labor employed by education between 1963 and 2011. Changes in the amount of labor employed of a given education level can be attributed to changes in: (i) the size of the population with that education level, (ii) hours worked by each worker, or (iii) the effective units of human capital per worker. We decompose the overall changes in labor employed into these three components. We also show how much of the change in high school or college equivalent labor is due to changes in labor supplied by those with less than a high school degree, with a high school degree, with some college, a college degree or more than a college degree.

Based on the flat-spot approach, we have data on effective units of human capital per worker. We also have data on the population size and hours worked for each year, birth cohort, education class and gender. Assume that individuals within cohort, education, and gender are homogenous in their human capital endowments. Denote the total amount of labor services provided by each birth cohort $b$, education group $e$, and gender $g$ in year $t$ by $L_{b, e, g, t}$ where $b=$ cohort, $e \in\{H S, C\}$ (that is, high school or college), $g \in\{M, F\}$ (that is, male or female). Then let $N_{b, e, g, t}, H_{b, e, g, t}$ and $Q_{b, e, g, t}$ respectively denote the population size, hours worked, and units of effective human capital (or quality units) by group and year, and:

$$
L_{b, e, g, t}=Q_{b, e, g, t} * H_{b, e, g, t} * N_{b, e, g, t}
$$

where $Q_{b, e, g, t}=W_{b, e, g, t} / R_{e, g, t}$. We can aggregate $L_{b, e, g, t}$ further across birth-cohorts within a year to obtain the overall labor supply $L_{e, g, t}$ and its components.

In Table 1 we show the total percentage changes in $L_{e, g, t}$ and the contribution of each education sub-category (drop-outs, high school graduates, some college, college graduates, and more than college) to the growth in labor supply of high school and college type labor between 1963 and 2011. ${ }^{5}$ Female labor supply grew very rapidly by 75.9 percent for high school type labor and an astonishing 809 percent for college type labor. The growth in labor for high school and college type males (21 percent and 291.5 percent respectively) is slower than that for women, but still very substantial. Growth in college type labor for both groups far exceeded that for high school type labor during the last half century. Examining the subgroups, we find that most of the growth in high school type labor comes from an increase

\footnotetext{
${ }^{5}$ Changes in the age/experience distribution will also affect the effective labor supply. We explored this possibility by age-adjusting the sample in the different years to a common age-distribution. That age distribution was obtained by pooling the data across the entire sample period 1963-2011. This had little effect on these results.
} 
in high school graduation rates. Labor supplied by high school drop-outs in fact decreased as older cohorts with high rates of dropping out of high school were replaced by younger cohorts for whom graduating from high school was the norm. The increase in the supply of college type labor is fueled by an increase in all three groups that supply college type labor: the largest increases come from those who graduated college irrespective of whether they acquired additional education subsequently. A smaller, but still substantial contribution to the increase in college type labor comes from those who obtain some college but did not complete 4 year degrees.

The lower half of Table 1 shows the annualized rate of growth of labor supply for 5 subperiods that each last a decade, except for the last period which covers only 8 years. Over time, growth in female labor supply has slowed for both high school and college type labor, but particularly female college labor. During the 1963-1992 period, female college labor grew by 5 to 7 percent annually, but since 1993 this growth rate has slowed to 2 percent. A similar slow down is observable among college educated males, although it has been more gradual over the entire period. Male high school labor has shown periods of both growth and decline. Female high school labor has increased during the first half of the time-period studied, but between 2003 and 2011 we observe that high school labor declines among both men and women.

Between 1973 and 1982, while the rate of growth of male high school labor was negative, growth in college type labor was rapid for both males and females. These patterns combined to lead to a rapid expansion in college type labor in this period. This expansion in college type labor and the subsequent turn-around during the 1980s and 1990s has been much commented on in the literature and provides much of the variation that identifies the labor demand estimates of KM and subsequent authors.

Table 2 disaggregates the growth in labor supply by education further into each of its subcomponents, quality $Q_{b, e, g}$, poopulation $N_{b, e, g}$ and hours $H_{b, e, g}$. Since $L_{e, g, b}$ is the product of these three components, the changes in these three components are compounding.

For men, there is little besides the change in the working age population that has contributed to the overall growth in labor supply regardless of education. In fact, among all but the most educated men, hours and quality decreased over the entire time period. It is only the overall increase in the number of working age men and particularly men with high education levels that drives the increase in labor supply.

Among women however, the contribution of hours is large both for college and high school type labor. As for men, quality declines for all but the most educated women. The 
rapid growth in hours combines with the rapid increase in the number of high school educated women and the truly staggering increase in the number of college educated women to generate the very rapid growth in labor supplied by working age women reported in Table 1.

To a large extent, the college educated workforce grew more slowly during the last two decades because educated women were not increasing their hours worked as much as they did during the 1970s and 1980s. For example, while annual hours of female college graduates grew by around 1.5 percent between 1973 and 1992, they have essentially held constant since 1993 (as have the hours of male college graduates). This slowdown in the growth of hours worked drives the slowdown in female college educated employment after 1983 since the growth in female working-age population with college degrees or more was maintained after 1983 .

Overall, the main trends over this time period are (i) secular growth in the college educated workforce, particularly among females and (ii) the rapid expansion of female labor supply relative to males. It will be difficult to continue expanding the relative supply of educated labor further once the catching-up process in hours worked and in female education has run its course.

\section{Estimating the Demand for Labor}

In the previous Section we described the trends in population, human capital endowments, and hours that shaped the supply side of the labor market between 1963-2011. Here we estimate how the demand for labor of different education levels and gender evolved. With 48 years, the time-series at our disposal is fairly short, forcing the production function to be very parsimonious. We follow KM and assume a CES production function with log-linear trends in the demand for labor of different types.

However, the specification by KM does not accommodate the increase in female labor force participation that coincided with a decline in the female wage gap between 1963 and 2011. To account for these trends, we expand on the KM framework and use a nested CES structure that allows for imperfect substitution across males and females of different education types. ${ }^{6}$

\footnotetext{
${ }^{6}$ A two-level nested CES production function was also employed by Card and Lemieux (2001) to study the wage-structure across education and experience during this period.
} 
Consider thus the simple nested 2-level CES form:

$$
F\left(L_{H S, M, t}, L_{H S, F, t}, L_{C, M, t}, L_{C, F, t} ; t\right)=\left(\widetilde{A}_{t}\left(\left(\alpha_{1 t} L_{\text {male }, t}^{\rho_{1}}+\left(1-\alpha_{1 t}\right) L_{f e m, t}^{\rho_{1}}\right)\right)^{1 / \rho_{1}}\right)
$$

This top-level production function takes two labor inputs $L_{\text {male, } t}$ and $L_{f e m, t}$. The parameters in Equation (2) are total factor productivity $\left(\widetilde{A}_{t}\right)$, the weight placed on the first input $\left(\alpha_{1, t}\right)$, and the parameter $\rho_{1}$ that governs the elasticity of subsitution between $L_{\text {male,t }}$ and $L_{f e m, t}{ }^{7}$ The weight $\alpha_{1, t}$ is allowed to vary with time and thus allows for differential trends. When $\alpha_{1, t}$ declines, then we say that technological change is biased against male labor - recognizing of course that the shift might represent social rather than technological phenomena that increase the demand for female as opposed to male labor. According to this parlance, declines in wage discrimination against women will be called technological change biased against male and in favor of female labor.

The indices $\left(L_{\text {male }, t}, L_{\text {fem }, t}\right)$ aggregate male high school and college educated labor $\left(L_{H S, M, t}, L_{C, M, t}\right)$ and female high school and college educated labor $\left(L_{H S, F, t}, L_{C, F, t}\right)$ respectively:

$$
\begin{aligned}
L_{\text {male }, t} & =\left(\alpha_{2 t}^{M} L_{H S, M, t}^{\rho_{2}^{M}}+\left(1-\alpha_{2 t}^{M}\right) L_{C, M, t}^{\rho_{2}^{M}}\right)^{1 / \rho_{M}} \\
L_{f e m, t} & =\left(\alpha_{2 t}^{F} L_{H S, F, t}^{\rho_{F}^{F}}+\left(1-\alpha_{2 t}^{F}\right) L_{C, F, t}^{\rho_{F}^{F}}\right)^{1 / \rho_{C}}
\end{aligned}
$$

The specification in Equations (2) and (3) aggregates high school and college labor of each gender first into an index of gender-specific labor and then describes the demand for male or female labor using these gender-specific aggregates. Alternatively, we could have aggregated first within education across the two genders to obtain education-specific labor aggregates. The choice of aggregation imposes different restrictions on which labor types are separable. The specification defined by Equations (2) and (3) imposes that labor inputs of the same gender are separable. Consequently, the relative rental rates earned by labor of high school and college type labor of the same gender depend only on the relative supply of high school and college type labor of the same gender and not on the relative supply of high school and college type labor of the other gender. Analogous restrictions are implied if we choose to aggregate across gender within education first. We do not have an a priori reason to prefer either of these specifications and both fit the relative wage series over 19632011 period quite well. It is therefore difficult to choose between these specifications and we

\footnotetext{
${ }^{7} \rho_{1}=\frac{\sigma_{1}-1}{\sigma_{1}}$
} 
present results for both.

For estimation, we assume that the $\log$ rental rates $\left(\ln R_{H S, M, t}, \ln R_{C, M, t}, \ln R_{H S, F, t}, \ln R_{C, F, t}\right)$ are subject to additional, possibly correlated additive errors $\left(\varepsilon_{H S, M, t}, \varepsilon_{H S, F, t}, \varepsilon_{C, M, t}, \varepsilon_{C, F, t}\right)$. We assume that $\ln \left(\frac{\alpha}{1-\alpha}\right)=\exp \left(b^{0}+b^{1} * t\right)$ for each of the share weights in Equations $(2)$ and $(3)$. The parameters $\left(b_{0}, b_{1}\right)$ are allowed to differ across each of these equations. Given the specification that aggregates education first within gender, this implies that we allow for the speed of skill-biased technical change to differ by gender. Estimating the demand structure in Equations (2) and (3) thus means estimating the parameters $\left(b_{M}^{0}, b_{M}^{1}, b_{F}^{0}, b_{F}^{1}, b_{1}^{0}, b_{1}^{1}, \rho_{1}, \rho_{M}, \rho_{F}\right) .^{8}$

Since we use a constant returns to scale production function, the relative rental rates depend on relative labor inputs only: ${ }^{9}$

$$
\begin{gathered}
\ln \left(R_{H S, M, t} / R_{C, M, t}\right)=\ln \left(\frac{\alpha_{2 t}^{M}}{1-\alpha_{2 t}^{M}}\right)+\left(\rho_{M}-1\right) \ln \left(\frac{L_{H S, M, t}}{L_{C, M, t}}\right)+\varepsilon_{1, t} \\
\ln \left(R_{H S, F, t} / R_{C, F, t}\right)=\ln \left(\frac{\alpha_{2 t}^{F}}{1-\alpha_{2 t}^{F}}\right)+\left(\rho_{F}-1\right) \ln \left(\frac{L_{H S, F, t}}{L_{C, F, t}}\right)+\varepsilon_{2, t} \\
\ln \left(R_{H S, M, t} / R_{H S, F, t}\right)=\ln \left(\frac{\alpha_{1 t}}{1-\alpha_{1 t}} \frac{\alpha_{2 t}^{M}}{\alpha_{2 t}^{F}}\left(\frac{L_{\text {male }, t}}{L_{\text {fem }, t}}\right)^{\rho_{1}-1} \frac{\left(L_{\text {fem }, t} / L_{H S, F, t}\right)^{\rho_{F}-1}}{\left(L_{\text {male }, t} / L_{H S, M, t}\right)^{\rho_{M}-1}}\right)+\varepsilon_{3, t} \\
\ln \left(R_{C, M, t} / R_{C, F, t}\right)=\ln \left(\frac{\alpha_{1 t}}{1-\alpha_{1 t}} \frac{1-\alpha_{2 t}^{M}}{1-\alpha_{2 t}^{F}}\left(\frac{L_{\text {male }, t}}{L_{\text {fem }, t}}\right)^{\rho_{1}-1} * \frac{\left(L_{\text {fem }, t} / L_{C, F, t}\right)^{\rho_{F}-1}}{\left(L_{\text {male }, t} / L_{C, M, t}\right)^{\rho_{M}-1}}\right)+\varepsilon_{4, t} .
\end{gathered}
$$

We thus do not examine overall productivity trends but rather analyze relative wage changes only. This implies that our projections for future wages will all be relative.

For estimation, note that the Equations (4) - (7) are linearly dependent and we therefore

${ }^{8}$ Here, $\left(b_{M}^{0}, b_{M}^{1}, b_{F}^{0}, b_{F}^{1}, \rho_{M}, \rho_{F}\right)$ denote the parameters that govern the demand for skilled and unskilled labor within gender. The parameters $\left(b_{1}^{0}, b_{1}^{1}, \rho_{1}\right)$ relate to the production function using the gender-specific inputs $\left(L_{\text {male }, t}, L_{f e m, t}\right)$. The notation for the parameters governing the gender first production function is analogously defined. $(3)$ :

${ }^{9}$ We obtain expressions that do not rely on the gender aggregates by substituting out using Equation

$$
\begin{aligned}
\ln \left(R_{H S, M, t} / R_{H S, F, t}\right)=\ln \left(\frac{\alpha_{1 t}}{1-\alpha_{1 t}} \frac{\alpha_{2 t}^{M}}{\alpha_{2 t}^{F}}\right) & +\left(\rho_{1}-1\right) \ln \left(\frac{\left(\alpha_{2 t}^{M}+\left(1-\alpha_{2 t}^{M}\right)\left(\frac{L_{C, M, t}}{L_{H S, M, t}}\right)^{\rho_{M}}\right)^{1 / \rho_{M}}}{\left(\alpha_{2 t}^{F}\left(\frac{L_{H S, F, t}}{L_{H S, M, t}}\right)^{\rho_{F}}+\left(1-\alpha_{2 t}^{F}\right)\left(\frac{L_{C, F, t}}{L_{H S, M, t}}\right)^{\rho_{F}}\right)^{1 / \rho_{F}}}\right) \\
& +\ln \left(\frac{\left(\alpha_{2 t}^{F}+\left(1-\alpha_{2 t}^{F}\right)\left(\frac{L_{C, F, t}}{L_{H S, F, t}}\right)^{\rho_{F}}\right)^{\left(\rho_{F}-1\right) / \rho_{F}}}{\left(\alpha_{2 t}^{M}+\left(1-\alpha_{2 t}^{M}\right)\left(\frac{L_{C, M, t}}{L_{H S, M, t}}\right)^{\rho_{M}}\right)^{\left(\rho_{M}-1\right) / \rho_{M}}}\right)^{1}
\end{aligned}
$$


limit ourselves to Equations (4), (5) and (6) when estimating this system. The system is also related because the unobservables $\varepsilon_{1, t}=\varepsilon_{H S, M, t}-\varepsilon_{C, M, t}, \varepsilon_{2, t}=\varepsilon_{H S, F, t}-\varepsilon_{C, F, t}$ and $\varepsilon_{3, t}=\varepsilon_{H S, M, t}-\varepsilon_{H S, F, t}$ are clearly correlated. Last and not least, this system of equations is non-linear and all parameters from Equations (4) and (5) appear in Equations (6) and (7). We estimate this system using GMM and thus exploit the cross-equation restrictions to estimate the parameters. ${ }^{10}$

Table 4, columns (1) and (3), shows estimates for both alternative ways of formulating the production function, aggregating gender or education first. Figures 3 and 4 show how the two specifications fit the data. For 1963-2011, we show the measured relative rental rates (from the flat-spot method) as well as the predicted relative rental rates using the estimated parameters. Clearly, both specifications are able to match the observed time-series of rental rates well and there is little basis on which to discard one specification in favor of the other.

There are long run declines in the rental rates of male relative to female labor and in the rental rates of high school relative to college type labor. Depending on the specification, the estimates indicate shifts of labor demand between 1 and 2 percent annually in favor of female relative to male labor and estimates between 1 to 2 percent annually in favor of college relative to high school type labor. In the data, the relative rental rates of college-type female labor increase particularly rapidly. Because of this, we find that the estimates of $b_{1}$ within Nest 2 are very high for both specifications indicating a shift in demand in favor of college educated relative to high school educated women in the education-first specification as well as college educated women relative to men in the gender-first specification.

The estimated elasticities of substitution between male and female labor are fairly high; depending on the specification they range between about 1.7 and 5.3. The estimated elasticities of substitution between high school vs. college type labor vary between 3 and 6.5. These estimated elasticities of substitution between high school and college is quite a bit higher than those typically reported in the literature. For instance, KM report values of 1.4 and Autor, Katz and Kearney (2008) values around 2 for this parameter. Because we use high elasticities of substitution in our main projection, this limits the impact that changes in the supply of different types of labor can have on relative wages. Elasticities of substitution between 1.4 and 2 by contrast allow for substantially larger effects of changes in the supply of labor on relative wages. Ultimately, this parameter is difficult to pin down in aggregate as the supply of High School and College type labor typically varies relatively slowly and

\footnotetext{
${ }^{10}$ To estimate the weighting matrix $\Omega$, we first estimate the system of equations using system non-linear least squares. Using the residuals from this first stage procedure, we then construct the weighting matrix to obtain the GMM estimates.
} 
this variation is required to identify this parameter. Therefore, when we project future wage structures in Section VI, we provide results both for our high estimated elasticities as well as the lower ones reported by previous authors.

\section{Baby-boom, Baby-bust and Endogenous Labor Sup- ply}

So far we have assumed that labor is exogenously supplied and that hours worked and participation do not respond to wages. However, if labor is endogenously supplied, then our estimates of the labor demand specification will be biased. Furthermore, to predict future wages we need to allow for an endgenous supply response. We thus need to consider both whether endogenous labor supply leads to endogeneity bias in our estimated labor demand structure and whether endogenous labor supply will significantly affect our projected future wage structure. To fix ideas and clarify the discussion, we assume that preference are quasilinear and thus abstract from income effects. This assumption allows us to parameterize future labor supply responses in a simple manner.

We begin by assuming that graduation rates, skill endowments, and the demographic composition of the US work-force over the last 50 years were exogenous and construct instruments for labor supply using these assumed exogenous drivers of labor supply. The identifying variation in these estimates derives largely from the growth in education across cohorts during the middle of the last century and from the substantial demographic variations known as the baby-boom and baby-bust. ${ }^{11}$ As we show below, the production function estimates obtained when assuming labor supply to be exogenous and when instrumenting using these demographic changes are quite close, suggesting that endogeneity bias due to labor supply is not a major concern.

In principle, we could use the variation induced in the wage structure due to changes in the demographic structure to estimate labor supply elasticities. However, we find that our estimates are sensitive to whether we use long-run or short-run variation in wages. Furthermore, our estimates vary substantially depending on whether we use the variation in the male-female wage gap over time or the variation in the returns to education to identify the

\footnotetext{
${ }^{11}$ Katz and Murphy (1992) and the literature following them rely on the same variation to identify the parameters of labor demand. They assume that labor supply is exogenous and use variation in the supply by different demographic and education groups to identify the labor demand parameters conditonal on the assumption of a linear trend in skill-biased technical change. Our approach in this Section is less restrictive since we allow for a endogenous labor supply response.
} 
labor supply elasticity. Fortunately however, there exists a rich literature estimating labor supply elasticities using other sources of variation. Since our estimates are very inconsistent across specifciations, we choose to rely on labor supply elasticities obtained from the literature for our predictions of what the US labor market will look like in 2030 in Sections V and VI.

\section{IV.A Labor Supply}

Equation (1) represents total labor services by $(b, e, g)$ at time $t$ as $L_{b, e, g, t}$ as the product of the size of the group (denoted $\left.N_{b, e, g, t}\right)$, average human capital $\left(Q_{b, e, g, t}\right)$, and average hours $\left(H_{b, e, g, t}\right)$ supplied. Total labor supply of type $(g, e, t)$ in a given period is obtained by summing across all birth-cohorts:

$$
L_{e, g, t}=\sum_{b} L_{b, e, g, t}=\sum_{b}\left(H_{b, e, g, t} * Q_{b, e, g, t} * N_{b, e, g, t}\right)
$$

Let $l_{e, g, t}=\ln L_{e, g, t}$.

The wage offer for hours worked by any individual in group $(b, e, g, t)$ is

$$
W_{b, e, g, t}=R_{e, g, t} * Q_{b, e, g, t}
$$

where $R_{e, g, t}$ is the rental rate for labor of type $(e, g)$ at time $t$. It is crucial for identification that $R_{e, g, t}$ does not depend on the birth cohort $b$.

We maintain the assumption that the number of individuals in a given group $(b, e, g)$ and their human capital endowments are exogenous to the system. For simplicity, we also assume that all individuals within a group have the same amount of human capital. Our innovation is to allow for endogenous labor supply. We allow $H_{b, e, g, t}$ to respond to rental rates to capture how workers adjust their labor supply at both the intensive and extensive margins.

\section{Preferences}

Quasi-linear utilities govern the choices over leisure and consumption. This has the convenient advantage that it eliminates income effects and dynamic considerations from the labor supply decision. All individuals conditional on $(b, e, g, t)$ are identical, so we can 
suppress the $i$ subscript. ${ }^{12}$ The utility function is:

$$
U\left(C_{b, e, g, t}, H_{b, e, g, t}\right)=C_{b, e, g, t}+\widetilde{\theta}_{b, e, g, t} H_{b, e, g, t}^{\gamma}
$$

and $\widetilde{\theta}_{b, e, g, t}<0$ because leisure is a good. An interior solution requires that $\gamma>1$. Individuals maximize this quasi-linear utility function subject to the budget set:

$$
Y+\left(R_{e, g, t} Q_{b, e, g, t}\right) H_{b, e, g, t}-C_{b, e, g, t}=0
$$

We obtain a log-linear function for hours supplied:

$$
h_{b, e, g, t}=\theta_{b, e, g, t}+\gamma * w_{b, e, g, t}
$$

where $w_{b, e, g, t}=\ln \left(W_{b, e, g, t}\right)=\ln \left(R_{e, g, t} Q_{b, e, g, t}\right)$ and $h_{b, e, g, t}=\ln \left(H_{b, e, g, t}\right)$. The parameter $\theta_{b, e, g, t}$ depends on $\widetilde{\theta}_{b, e, g, t}$ and is for now unrestricted, even though we obviously have to restrict this parameter for estimation.

\section{IV.B The Endogeneity Problem}

The non-linear system of Equations (4)-(7) represents the demand for labor in period $t$. For simplicity, denote the 4-dimensional vector of dependent variables in this system as $r_{t}$ and collect the unobservables in the vector $\varepsilon_{t}$. This allows us to write the rental rate equations in shorthand as:

$$
r_{t}=F\left(l_{H S, M, t}, l_{H S, F, t}, l_{C, M, t}, l_{C, F, t}, t ; \chi\right)+\varepsilon_{t} .
$$

The independent variables $l_{e, g, t}$ in Equation (11) are functions of the hours supplied by all cohorts. But, from Equation (10), we find that hours depend on $w_{b, e, g, t}=r_{e, g, t}+q_{b, e, g, t}$. Thus, the dependent variable from Equation (11) enters in Equation (10) and vice versa. This is of course just the familiar problem of estimating a supply and demand system using data on prices and quantities only. Identification requires exclusion restrictions.

${ }^{12}$ The assumption that all individuals are identical is not without consequence for the estimating equation. The estimating equation will be written in logs and the non-linearity can interact with dispersion in ways to invalidate the estimating equation. For now, the argument is simplified by assuming that there is not variation within group. 


\section{IV.C Estimating the Labor Demand System}

We estimate the labor demand system assuming that the quality, or effective units of human capital, and the size of each group indexed by $(b, e, g, t)$ are exogenous: $Q_{b, e, g, t}, N_{b, e, g, t} \perp$ $\varepsilon_{t}$. This orthogonality assumption asserts that, conditional on a time-trend, the quality changes across cohorts as well as the demographic changes induced by the varying cohort sizes are independent of changes in labor demand. This assumption is by no means innocuous since it assumes that the quality of education does not respond to the demand for skilled labor.

Based on this exogeneity assumption, we instrument for labor supplied with quality and average hours adjusted group size. That is, we aggregate individuals in group $(g, e)$ at $t$ as follows:

$$
l_{e, g, t}=\ln L_{e, g, t}=\ln \left(\sum_{b} Q_{b, e, g, t} N_{b, e, g, t} \bar{H}_{e, g, t-b}\right) .
$$

Here $\bar{H}_{e, g, t-b}$ represents average hours supplied by individuals of education $e$ and gender $g$ at age $t-b$ and is obtained as $\bar{H}_{e, g, a}=\frac{1}{\# B} \sum_{b} H_{b, e, g, t=b+a}$. We then use the four log differences $\left(l_{H S, M, t}-l_{C, M, t}\right),\left(l_{H S, F, t}-l_{C, F, t}\right),\left(l_{H S, M, t}-l_{H S, F, t}\right)$ and $\left(l_{C, M, t}-l_{C, F, t}\right)$ to instrument for labor in the the non-linear system in Equation (11). The identifying variation comes from changes in the relative quality by cohort and cohort sizes by gender and education.

\section{First Stage}

For 2SLS, a large literature warns of the danger of using weak instruments and explores how IV methods perform when the correlation between the instruments and the endogenous variables varies. There is no clear analog for non-linear least squares, but the basic concern carries through to non-linear approaches: if the instrument is weak, then the least squares projections in the first stage of the estimation will in small samples "try" to fit all of the variation in the data, regardless of whether it is endogenous or exogenous. In our application, we find that the instruments are strong predictors of the endogenous variables. In Table 3 we present regression evidence that shows that the instruments and the endogenous variables are highly positively correlated after controlling for trends. In all four cases the partial Fstatistic on the instrment is above 10. Overall, these instruments tend to be highly correlated with the endogenous variables. For all four specifications the $R^{2}$ is above 0.9 and therefore most of the variation in labor supply over time seems to be captured by time-trends, by 
changes in the quality of education across cohorts, and by broad demographic changes.

\section{The Production Function Estimates}

The production function estimates are typically quite close to the OLS ones, presumably because the first stage has such a high $R^{2}$. These parameter estimates are shown in Table 4, columns (2) and (4) and Figures 5 and 6 show the fit.

The estimates for the elasticity of substitution are fairly close to those obtained assuming exogenous labor supply while the estimated trends towards both female and college type labor are almost identical. The similarities between the OLS and the IV estimates suggest that there is little endogeneity bias in the estimates of labor demand obtained previously.

\section{IV.D Parameterizing the Supply of Labor}

Even though we find little evidence for endogeneity bias, we need to nevertheless parameterize the supply of labor (as per Equation (10)) to predict future labor supply and wages.

We had little success estimating labor supply parameters. To instrument for wages in the labor supply equations, we used predicted wages based on the estimated production function using the IV approach described in the previous sub-section. Our estimated longrun variation in labor supply across gender is consistent with a positive supply response of females relative to males in response to the declining wage gap. However, the change in female relative to male labor supply is too large to be reconciled with standard labor supply estimates in the literature. From our data, we obtain labor supply elasticities of 0.82.3 in response to the long run changes in male-female wage gaps, much larger than those typically reported. The labor supply response estimated using changes in the male-female wage gap are also much larger than those obtained when comparing college and high school educated workers within gender. Furthermore, the sign on the estimated supply response flips when we control for trends and rely on short-run variation in wages for identification. These inconsistent findings are useful reminders that social trends and forces other than wages contribute to observed changes in labor force participation and hours worked during this time period. It is naive to expect the short, aggregate time-series available using the CPS to identify supply elasticities in labor supply. We thus turn to the literature to provide credible parameter estimates to calibrate the labor supply elasticities in our projections.

Chetty (2012) provides bounds on labor supply elasticities estimated in the presence of 
frictions. He estimates bounds on the labor supply elasticities that would be observed in a frictionless world but consistent with pre-specified levels of frictions. These bounds are informative for long-run responses to wage changes after frictions have dissipated and are thus appropriate for forming our long-run projections. Chetty reports bounds on Hicksian elasticities. With quasi-linear preferences the Hicksian, Marshallian, and Frisch elasticities all coincide, which allows us to readily transfer his results to our setting. Chetty reports bounds based on 23 studies, exploiting life-cycle variation in wages, tax reforms, non-linearities in budget constraints, long-run variation in wages for both men and women in the US between 1980 and 2000, as well as cross-country tax variation. The reported Hicksian elasticities from these studies vary between 0 and 1.07. Based on these studies, Chetty reports a lower bound on the structural labor supply elasticity of 0.47 and an upper bound of 0.51 . The 95 percent confidence interval on the lower bound reaches as low as 0.23 and the 95 percent CI on the upper bound goes as high as 0.53. Overall, the synthesis of the literature on labor supply provided by Chetty suggests a positive, but modest labor supply elasticity. In the analysis below, we assume a labor supply elasticity of $0.5 .{ }^{13}$

\section{Estimating the Effective Labor Force}

To complete our specification of labor supply, we also need to predict the structure of the labor force by education, age, and gender over the next few decades. This requires predicting how many individuals of different ages and gender there will be in any year through to 2030, how much education they will have, and the units of effective human capital each of them will potentially supply to the market.

\section{V.A Population Size}

The first step is to obtain an estimate of how many males and females of different ages there will be in future years in the US. From the CPS data up to 2011, we can obtain estimates of the size of each cohort-gender group alive in 2011 for all cohorts born prior to 2011. From the Census Bureau's 2008 National Population Projections (NPP) ${ }^{14}$ we obtain

\footnotetext{
${ }^{13}$ We assume the same labor supply elasticity of 0.5 for both men and women although the labor supply elasticity for women is generally thought to be larger than that for men. However, Chetty's analysis comprised studies of both men and women and furthermore, by setting the supply elasticities equal for men and women we will attain a more conservative prediction in terms of the potential labor supply response.

${ }^{14}$ See Appendix A for further details on this data.
} 
predictions for the size of future cohorts relative to those that are already born. ${ }^{15}$ Our baseline estimates from the CPS can thus be combined with the data from the NPP to obtain estimates of the demographic structure of the US up to 2030. The 2011 and 2030 age structure within the working age population is shown in Figure 7 . The NPP projections imply no effect of the ageing population on the age structure within working ages. We do observe that the baby boomers (aged between 45 and 54 years in 2011) have aged out of the working age population by 2030 .

\section{V.B Education}

We proceed to impute educational attainment for those cohorts that have not completed schooling by 2011. For this, we extrapolate how educational attainment changes among cohorts born after 1960. These changes include a response to the turnaround in the returns to education observed in recent decades. As such, our extrapolations capture potential educational upgrading that occurs because the returns to education have increased. ${ }^{16}$

We first determine the share of each cohort that achieves at least a given level of education. For example, we use respondents of ages 22-25 to measure the proportion of high school dropouts in a given cohort. Similarly, we measure the share of high school graduates using 24-28 year olds, the share of college completers using 26-30 year olds, and the share of those with more than a college degree using 30-34 year olds. We observe cohorts born before 1981 until at least age 30 (in 2011) and can thus generate the distribution of completed education for all cohorts born prior to 1981. For cohorts born between 1982 and 1989, we rely on a combination of direct measurements and extrapolations to predict their completed education distribution. For instance, for those born in 1984, we have data on educational attainment up to age 27. We can thus base our estimates of the share that drops-out of high school in this group on the data from ages 22-25. Similarly, we can estimate the share of high school graduates in the 1984 cohort using the data for this cohort for ages 24-27 and we can use the data from ages 26 and 27 to estimate the share that completes college. We do not have estimates of how many of this cohort will continue on to obtain more than a college degree. Thus, for the 1984 cohort we rely on direct measurement of the high school drop-out rate, the share of some college and the rate of college completion. To obtain the share with more than a college degree, we need to rely on an extrapolated probability based on earlier cohorts.

\footnotetext{
${ }^{15}$ The Census Bureau obtains these NPP estimates largely by extrapolating based on historically observed mortality and fertility rates.

${ }^{16}$ An alternative to extrapolating educational attainment based on observed trends would be to relate attainment to the returns to education. We leave this task to future work.
} 
In particular, we extrapolate linearly using the trends in the probability of continuing after college observed using the 1960-1981 cohorts. By multiplying the estimated probability of continuing after college with the observed share of those with a college degree in the 1984 cohort, we obtain our predicted share of the 1984 cohort that attains more than a college degree.

We proceed in a similar manner to predict educational attainment for all cohorts born after 1981. The more recent a cohort is, the more we need to extrapolate. For cohorts between 1982 and 1989, our estimates are at least partially based on direct observation. For cohorts after 1989, we depend entirely on extrapolations.

Figures 8 and 9 show how the education distribution changes across cohorts for males and females. The share of individuals with high school degrees or less will continue to decline, with most of this decline coming from the group of high school completers. As we know from Heckman and LaFontaine (2010), the share of high school drop-outs has changed little over the last few decades and is therefore also projected to stay constant over the next decades. However, a larger and larger share of each cohort of high school graduates is predicted to continue schooling and thus the share of high school graduates itself continues to decline in future cohorts. The decrease in the share of future cohorts with high school or less is, by necessity, matched by an increase in the share with at least some college. Here, we expect both the share of cohorts with some college and the share that graduated from college to continue to increase. Similarly, the share with more than college will continue to rise, albeit from a relatively small base.

On current trends, a wide gulf in educational attainment between males and females is likely to open in the next few decades. Education upgrading over the last decades has proceeded a lot more rapidly among women than men. Based on this trend, we expect women to continue to attain higher education at a more rapid pace than men. These trends are particularly dramatic at the upper end of the education distribution. We for instance project that among cohorts born today, more than 40 percent of women will continue with some schooling after college, but less than 20 percent of men will do so.

\section{V.C Quality per cohort}

Next, we need to assign average human capital to future cohorts of different education types. For this, for each gender and education cell, we project measures of the observed quality, or effective units, of human capital obtained from the flat-spot method on entirely unrestricted age profiles and entirely unrestricted cohort profiles for all cohorts up to 1960. 
For the cohorts born in 1960 or later, we impose a linear trend on the change in human capital with the cohort. Thus, the regression equation for the projections within each of schooling and gender group is given by:

$$
\begin{aligned}
\hat{Q}_{b, a, e, g} & =\sum_{a \in\{18, . ., 65\}} 1\left(\text { age }_{i}=a\right) \beta_{a, e, g}^{(1)} \\
+ & \sum_{b \in\{1897, \ldots, 1960\}} 1\left(\text { cohort }_{i}=b\right) \beta_{b, e, g}^{(2)}+1\left(\text { cohort }_{i}>1960\right)\left(\text { cohort }_{i}-1960\right) \beta_{g, e}^{(3)}
\end{aligned}
$$

Based on this projection, we can obtain predicted quality for cohorts that are not in the market yet and we can account for changes in human capital over the life-cycle for those that are currently working. Figure 10 shows the predicted quality of white females for birth cohorts through 2010. It shows our preferred predictions which impose the linear trend for cohorts born in 1960 and later as well as the prediction obtained for cohorts up to 1980 without imposing linearity for cohorts born after $1960 .{ }^{17}$

We use these projections to assign average human capital to each cohort in the labor market up to 2030. For cohorts up to 1960, the cohort effects are directly measured and the procedure amounts only to using the observed age-profiles $\left\{\beta_{a, e, g}^{(1)}\right\}$ to account for changes in human capital over the life-cycle. For cohorts after 1960, the cohort effects are assigned based on Equation (13). However, for cohorts born prior to about $1990^{18}$ these assignments are not extrapolations, since the trends $\left\{\beta_{g, e}^{(3)}\right\}$ are estimated based on observed earnings for these cohorts. For cohorts born after 1991, these assignments represent pure extrapolations. Thus, the share of data for which we need to extrapolate human capital endowments increases gradually as we move into the future. ${ }^{19}$

\footnotetext{
${ }^{17}$ Figure 10 does not show the predicted quality for cohorts prior to 1920, since these are typically based on very few observations and are quite noisy.

${ }^{18}$ The exact end-date for this depends on the education level. For high school graduates and high school drop-outs, we observe earnings for at least one year for cohorts up to 1991. For those with some college, the last cohort for which we observe at least one year of earnings data was born in 1990. For college graduates these last cohorts with earnings data are 1988 and 1986.

${ }^{19}$ It should be noted that even in 2030 the human capital levels assigned to workers older than about 40 years are not pure extrapolations. Instead, they are at least partially based on earnings observed prior to 2010 .
} 


\section{The Labor Market in 2030}

We are now in a position to combine the estimates of labor demand with the projected labor supply changes to obtain predicted equilibrium rental rates and labor employed for the next two decades. These estimates are based on the projected structure of the labor force described in Section V, an assumed labor supply elasticity of 0.5 based on the parameterization described in Section IV.D, and the predicted changes in the demand for labor implicit in the estimates reported in Table 4, column 2. Our exercise is exclusively based on relative wages and our rental rate projections are similarly exclusively about relative rental rates. We show how rental rates of high school males and of high school and college educated females will change relative to those earned by college educated males in 2011. We also normalize the rental rates for all types of human capital to 1 in 2011, since we can only identify changes in human capital rental rates and quality units of human capital by labor type. Quality units of human capital by type are thus measured in 2011 dollars.

To begin, consider the relative rental rates per unit of human capital as shown in Table 6. The projection suggests that the percentage growth in rental rates over the next 20 years will continue to favor women and college educated workers and in particular college educated women. With endogenous labor supply, we find that rental rates for female college labor will appreciate by about 18 percent relative to college educated males and 29 percent relative to high school educated males. Among males, rental rates for high school relative to college human capital will decline by about 11 percent. High school educated males are therefore likely to continue to lose ground in the labor market relative to all other groups, whereas females and particularly educated females are predicted to benefit significantly from projected trends in the labor market.

Accounting for endogenous changes in labor supply is important for the magnitude of these trends. For instance, without accounting for endogenous labor supply, we predict that the rental rates for college-educated females prices will grow by 36 percent relative to those of high school educated males. This contrasts with the 29 percent gap in growth when we allow for endogenous labor supply responses. ${ }^{20}$

These projected changes in the rental rates do not explore how changes in the units of

\footnotetext{
${ }^{20}$ The predicted relative rental rates in column 4 of Table 6 are calculated using endogenous labor supply and the lower elasticity of substitution between high school and college labor of 2.0 in line with Autor, Katz and Kearney (2008). As expected, the lower elasticity of substitution allows the moderating effects of the labor supply response to have a larger impact. Thus, we observe a slightly smaller increase in the relative rental rates of college educated women and a more moderate decline in the relative rental rate of high school educated men.
} 
human capital contribute to shifts in the earnings of different groups. As discussed above, human capital endowments conditional on education fall across the female cohorts born between 1950 and 1980. Based on this trend, we project the decline to continue. And, as older cohorts with more human capital per worker retire, the average human capital per female worker employed will also decline during the next 20 years. We are somewhat uncomfortable with this prediction, since part of the observed decline in human capital across the 1950-1980 cohorts might well be caused by increased labor force participation. That is, we are worried that as more women have participated in the labor force, they might be have been drawn from further down the quality distribution. The simple fact that labor force participation rates among more recent cohorts are very high implies that this increase in labor force participation can not be replicated in the near future. It is therefore especially difficult to predict how quality among female workers will evolve in future based on the trends observed in recent decades.

Nevertheless, we find that predicted trends in cohort quality will at least partially limit the gains of females relative to males, conditional on education. Table 7 shows how we expect average wages by schooling group and gender for 45 year olds to change between 2011 and $2030 .^{21}$ The table breaks out the contribution of changes in quality endowments and changes in rental rates to the overall change (that is, columns 2 and 3 sum to the value in column 1). These results are again relative to male college educated workers. Table 7 also shows the (within-gender) percentages of individuals falling in the different education groups. Note that 45 year olds in 2030 were born in 1985 and are 27 years old when they age out of our data. Their schooling choices and for many of them the beginning of their careers are thus only partially observed towards the end of our data.

The predicted variation in wages affects hours worked significantly. With a labor supply elasticity of 0.5 , the relative shifts in wages documented in Table 7, column (2) imply that average hours worked by high school educated women will increase by about 6-7 percent relative to those of similarly educated men. Hours worked by men with a high school degree or less will decline by about 7 percent relative to those of college educated males. Lastly, hours worked by women with a college degree or more are predicted to increase by 2-3 percent relative to those of similarly educated males over the next 20 years. The trends in education across cohorts and the hours response to the changes in wages due to endogenous labor supply responses imply that the workforce continues to be increasingly skilled and increasingly female.

\footnotetext{
${ }^{21}$ Unless explicitly indicated, the results that follow allow for endogenous labor supply.
} 


\section{References}

Altonji, Joseph G, Prashant Bharadwaj, and Fabian Lange. 2012. "Changes in the Characteristics of American Youth: Implications for Adult Outcomes." Journal of Labor Economics, 30(4): 783-828.

Autor, David H, Lawrence F Katz, and Melissa S Kearney. 2008. "Trends in US Wage Inequality: Revising the Revisionists." The Review of Economics and Statistics, 90(2): 300-323.

Boozer, Michael A, Alan B Krueger, and Shari Wolkon. 1992. "Race and School Quality Since Brown v. Board of Education." Brookings Papers on Economic Activity. Microeconomics, 1992: 269-338.

Bowlus, Audra J, and Chris Robinson. 2012. "Human Capital Prices, Productivity, and Growth." American Economic Review, 102(7): 3483-3515.

Card, David, and Alan B Krueger. 1992. "School Quality and Black-White Relative Earnings: A Direct Assessment." The Quarterly Journal of Economics, 107(1): 151-200.

Card, David, and Thomas Lemieux. 2001. "Can Falling Supply Explain the Rising Return to College for Younger Men? A Cohort-Based Analysis." The Quarterly Journal of Economics, 116(2): 705-746.

Carneiro, Pedro, and Sokbae Lee. 2011. "Trends in Quality-Adjusted Skill Premia in the United States, 1960-2000." American Economic Review, 101(6): 2309-2349.

Chetty, Raj. 2012. "Bounds on Elasticities With Optimization Frictions: A Synthesis of Micro and Macro Evidence on Labor Supply." Econometrica: Journal of the Econometric Society, 80(3): 969-1018.

Heckman, James J, and Paul A LaFontaine. 2010. "The American High School Graduation Rate: Trends and Levels." Review of Economics and Statistics, 92(2): 244-262.

Heckman, J, L Lochner, and C Taber. 1998. "Explaining Rising Wage Inequality: Explorations with a Dynamic General Equilibrium Model of Labor Earnings with Heterogeneous Agents." Review of Economic Dynamics, 1-58.

Katz, Lawrence F, and Kevin M Murphy. 1992. "Changes in Relative Wages, 19631987: Supply and Demand Factors." The Quarterly Journal of Economics, 107(1): 35-78. 
Lemieux, Thomas. 2006. "Increasing Residual Wage Inequality: Composition Effects, Noisy Data, or Rising Demand for Skill?" American Economic Review, 461-498. 
Figure 1: Human Capital Rental Rates, Males, 1963-2011
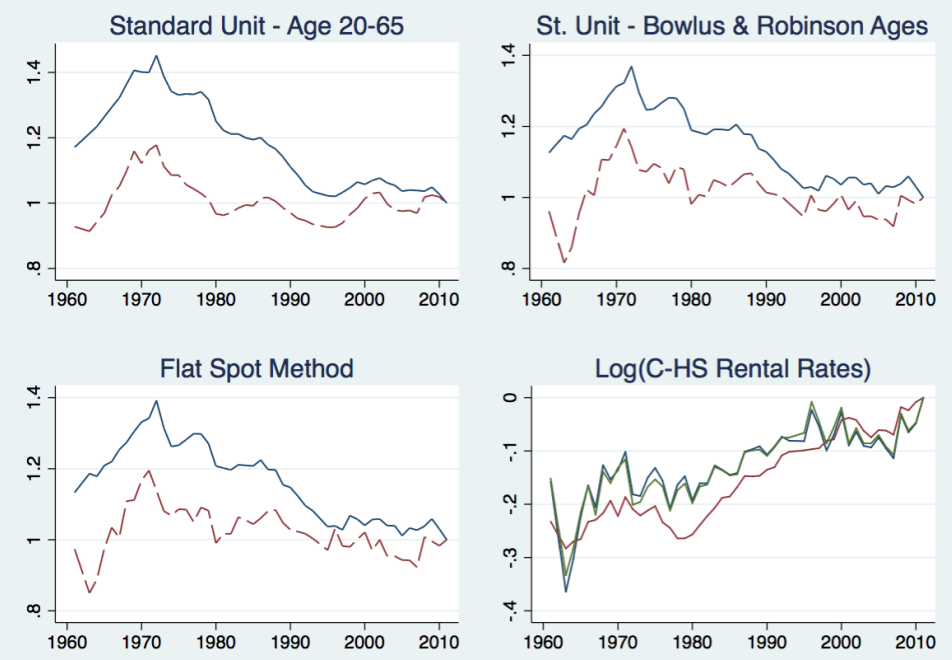

All rental rates are normed to 2011. In the panels labelled 'Standard Unit' and 'Flat Spot Method', the solid and dashed lines depict the rental rates for high school and college human capital respectively. In 'Log(C-HS Rental Rates)', each line depicts the relative college to high school rental rates. The red line is the ratio for the standard unit approach for 20-65 year olds, the blue line is the ratio for the standard unit approach for the BR ages and the green line depicts the ratio from the flat spot method.

Figure 2: Human Capital Rental Rates, Females, 1963-2011
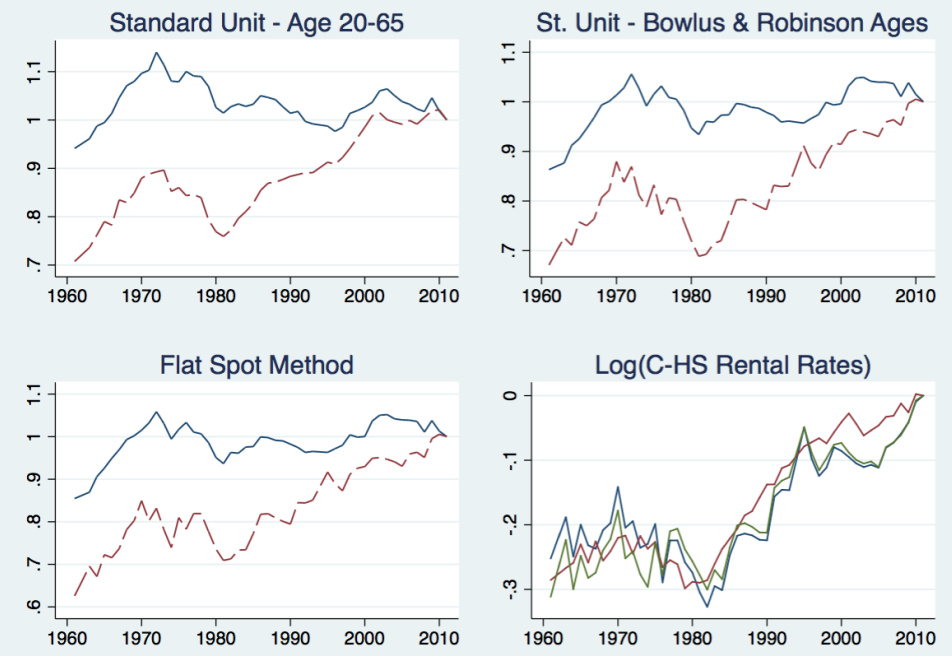

All rental rates are normed to 2011. In the panels labelled 'Standard Unit' and 'Flat Spot Method', the solid and dashed lines depict the rental rates for high school and college human capital respectively. In 'Log(C-HS Rental Rates)', each line depicts the relative college to high school rental rates. The red line is the ratio for the standard unit approach for 20-65 year olds, the blue line is the ratio for the standard unit approach for the BR ages and the green line depicts the ratio from the flat spot method. 
Figure 3: Fit of CES structure with Gender First Production Function and Exogenous Labor Supply
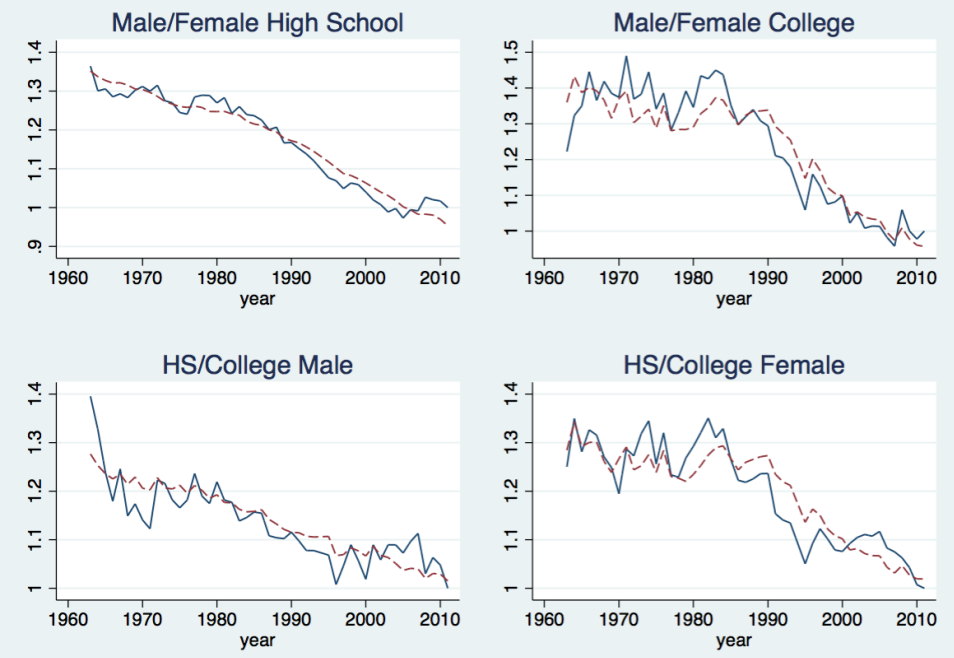

All rental rates are normed to 2011. The solid line depicts observed rental rates and the broken line depicts the fitted rental rates from GMM estimation of the system of equations $(4-7)$ (adjusted to estimate the substitution across gender in the inner nest) assuming exogenous labor supply.

Figure 4: Fit of CES structure with Education First Production Function and Exogenous Labor Supply
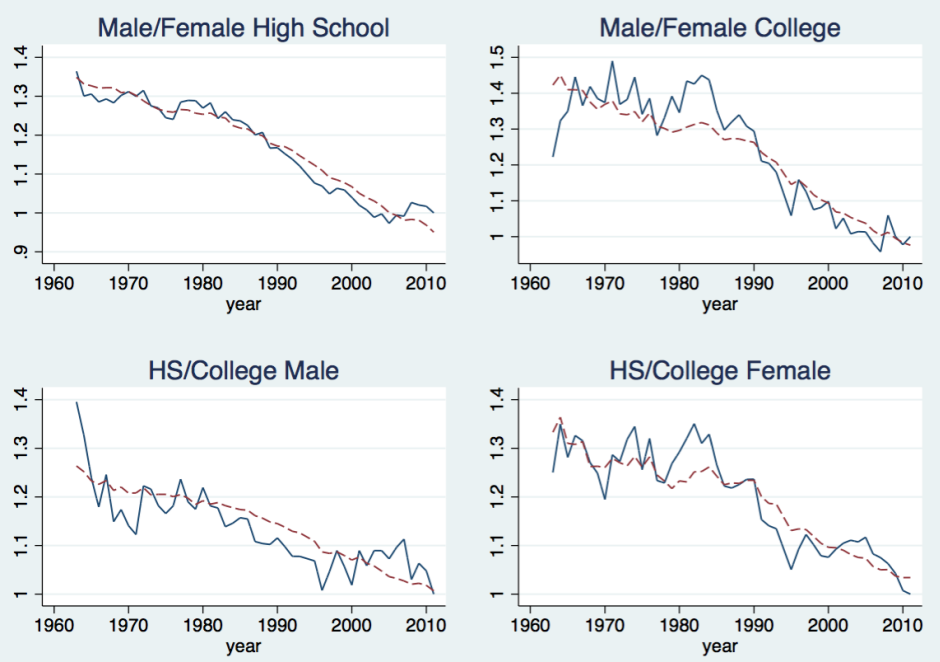

All rental rates are normed to 2011. The solid line depicts observed rental rates and the broken line depicts the fitted rental rates from GMM estimation of the system of equations $(4-7)$ assuming exogenous labor supply. 
Figure 5: Fit of CES structure with Gender First Production Function and Endogenous Labor Supply
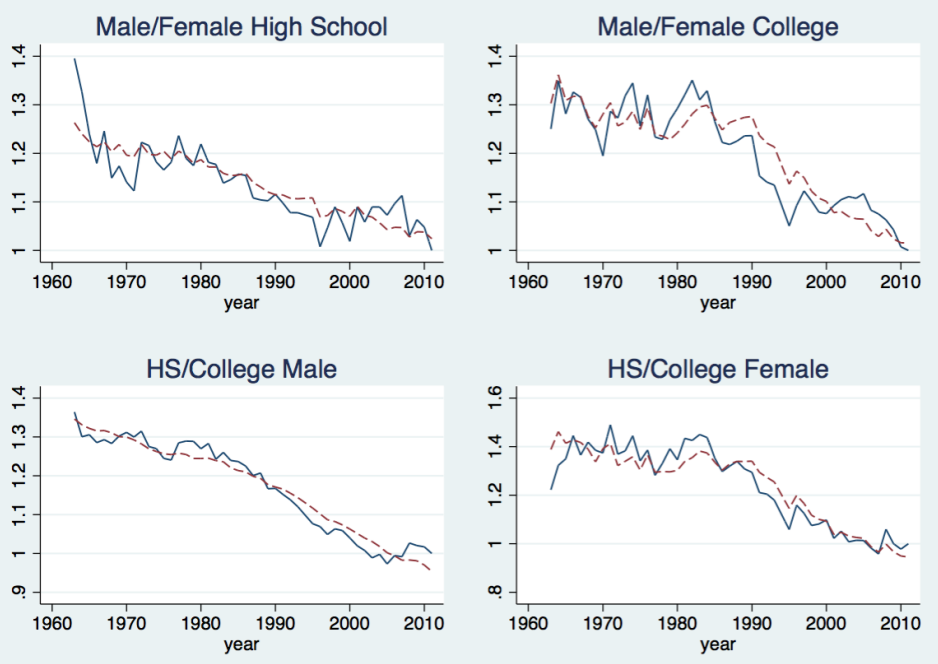

All rental rates are normed to 2011. The solid line depicts observed rental rates and the broken line depicts the fitted rental rates from GMM estimation of the system of equations (4-7) (adjusted to estimate the substitution across gender in the inner nest) instrumenting for endogenous labor supply with quality and average hours adjusted group size.

Figure 6: Fit of CES Structure with Education First Production Function and Endogenous Labor Supply
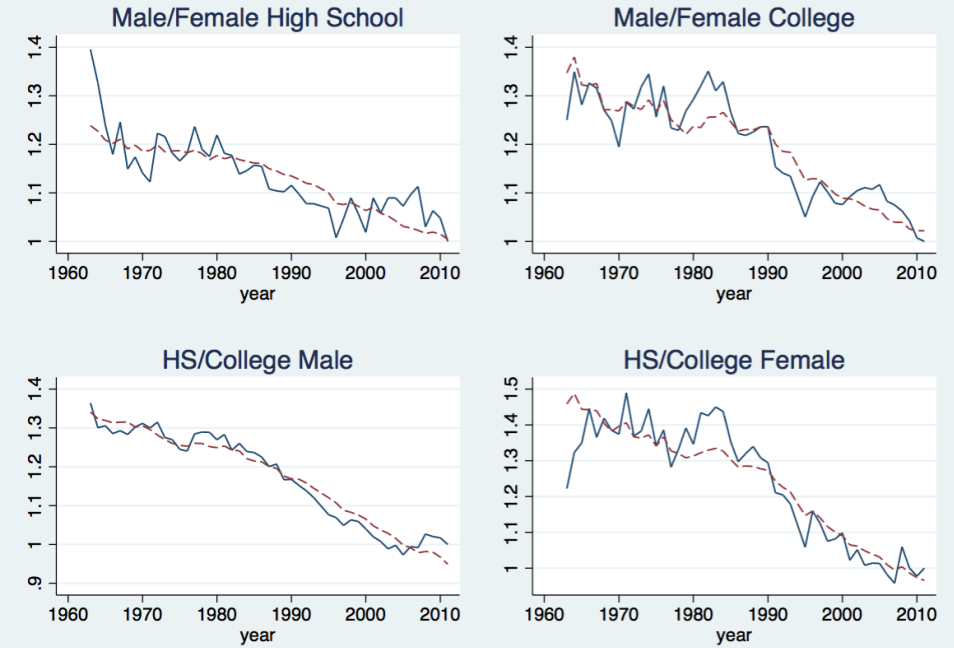

All rental rates are normed to 2011. The solid line depicts observed rental rates and the broken line depicts the fitted rental rates from GMM estimation of the system of equations $(4-7)$ instrumenting for endogenous labor supply with quality and average hours adjusted group size. 
Figure 7: Projected Age Structure, 2011 and 2030

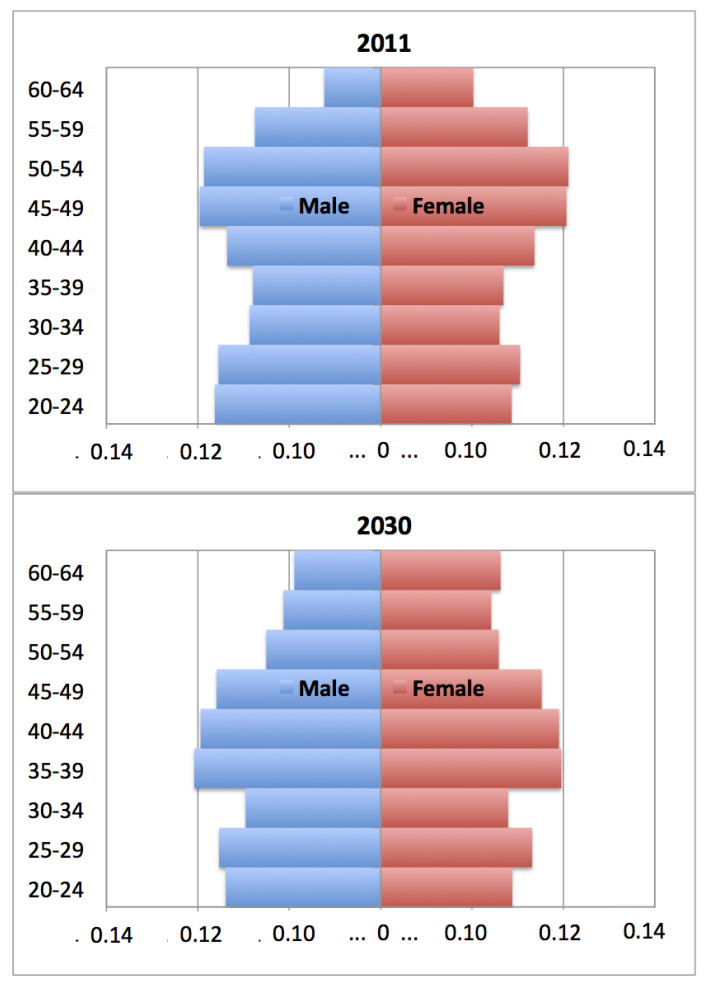

The figures show the proportion of the working age population in each age range, 20-24 years through to 60-64 year.

Figure 8: Education distribution by cohort - Males

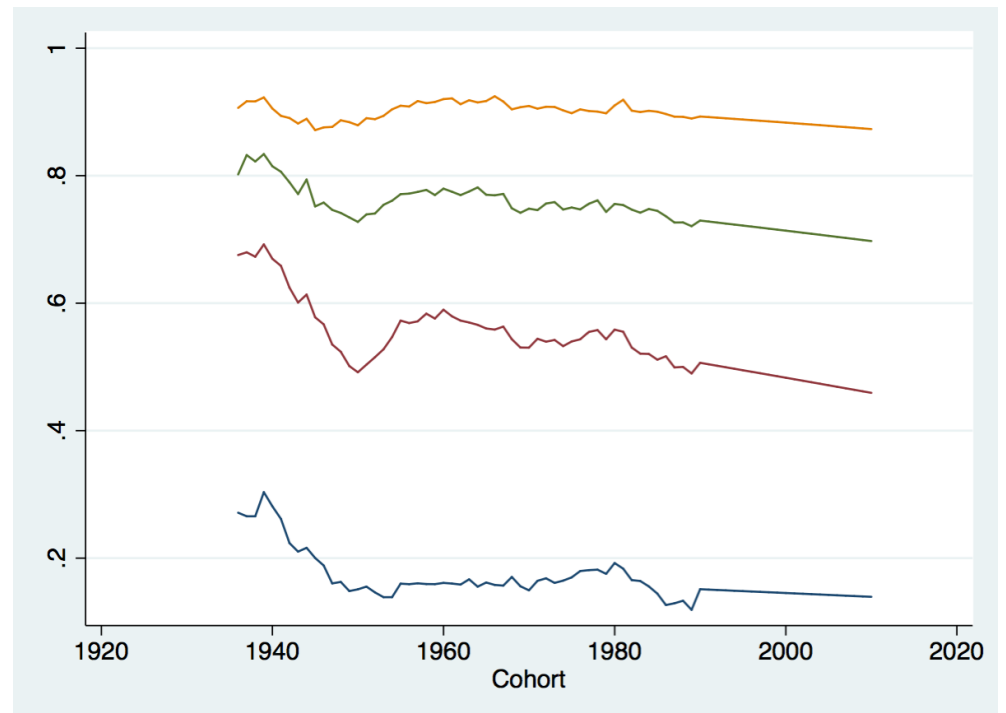

The figure shows the cumulative share of men, by birth cohort, with less than a high school degree (blue), a high school degree (red), some college (green) and college (yellow) from bottom to top. The remaining share above the top yellow line is the share of men with more than a 4-year college degree. 
Figure 9: Education distribution by cohort - Females

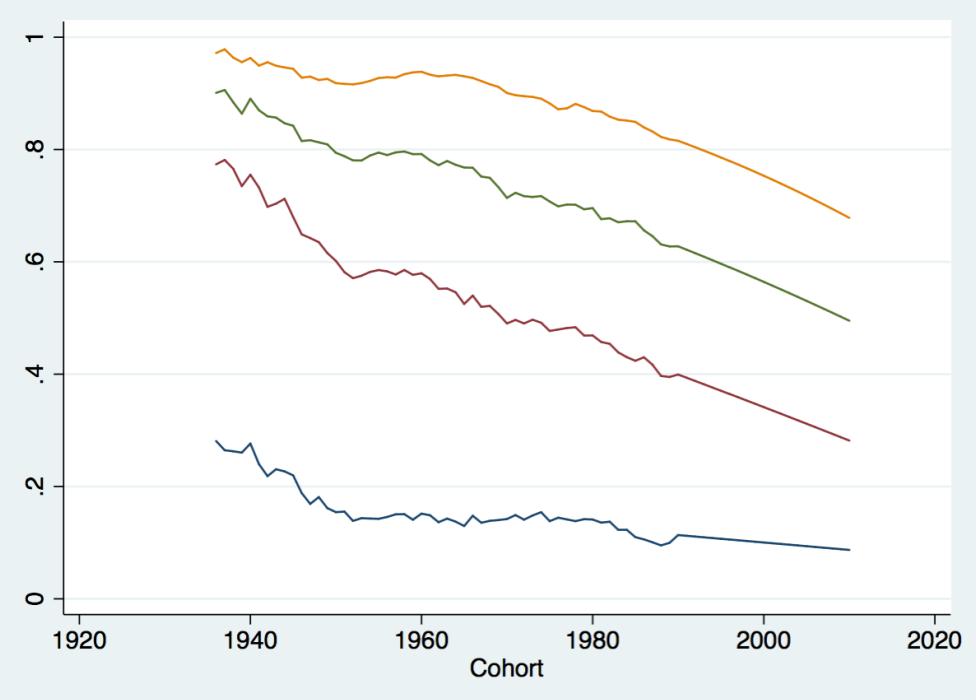

The figure shows the cumulative share of women, by birth cohort, with less than a high school degree (blue), a high school degree (red), some college (green) and college (yellow) from bottom to top. The remaining share above the top yellow line is the share of women with more than a 4-year college degree.

Figure 10: Predicted Quality of White Females at Age 30 by Education
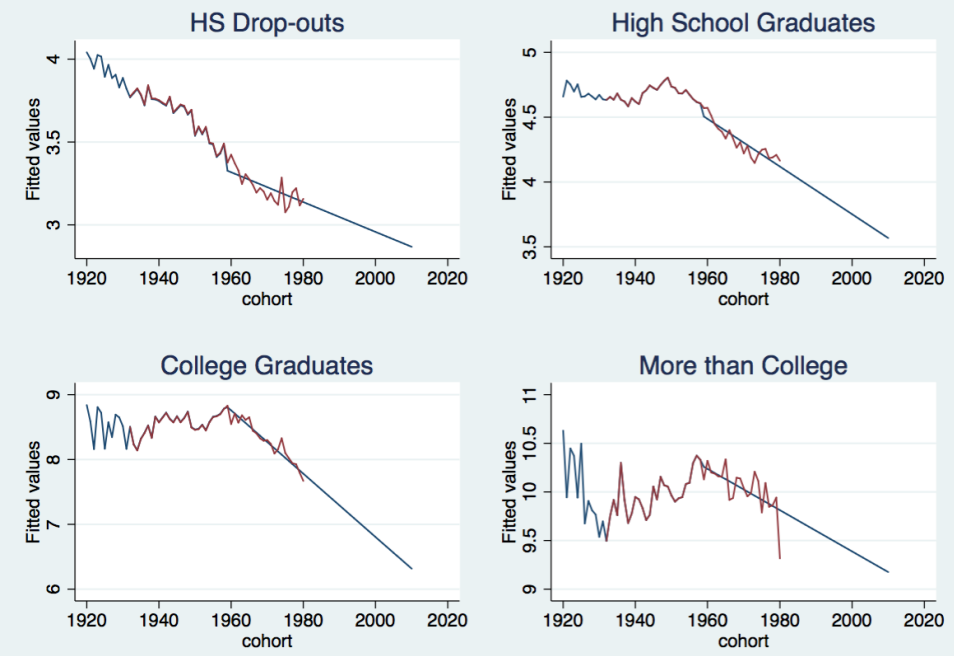

In each panel, the blue line is our preferred predicted quality for birth cohorts through to 2010 with a linear trend in predicted quality imposed for cohorts born in 1960 or later. The red line shows the predicted quality for birth cohorts thourgh 1980 without imposing linearity. 
Table 1: Changes in Labor Supply over the 1963-2011 Period

\begin{tabular}{|c|c|c|c|c|}
\hline \multirow[b]{3}{*}{ Period } & \multicolumn{2}{|c|}{ Men } & \multicolumn{2}{|c|}{ Women } \\
\hline & \multirow{2}{*}{$\begin{array}{c}\text { High School } \\
\text { or } \\
\text { equivalent }\end{array}$} & \multicolumn{3}{|c|}{ High School } \\
\hline & & $\begin{array}{l}\text { College or } \\
\text { equivalent }\end{array}$ & $\begin{array}{l}\text { or } \\
\text { equivalent }\end{array}$ & $\begin{array}{l}\text { College or } \\
\text { equivalent }\end{array}$ \\
\hline \multicolumn{5}{|c|}{ Total percentage change in labor supply } \\
\hline $1963-2011$ & 21.0 & 291.5 & 75.9 & 809.0 \\
\hline \multicolumn{5}{|c|}{ Percentage point contribution from } \\
\hline$<\mathrm{HS}$ & -28.7 & - & -18.7 & - \\
\hline HSG & 30.5 & - & 50.9 & - \\
\hline Some coll. & 19.2 & 48.7 & 43.8 & 145.8 \\
\hline Coll. grads & - & 126.2 & - & 344.6 \\
\hline$>$ Coll & - & 116.6 & - & 318.6 \\
\hline \multicolumn{5}{|c|}{ Percentage changes in labor supply, annualized rates by decades } \\
\hline $1963-1972$ & 1.56 & 4.61 & 2.87 & 7.09 \\
\hline 1973-1982 & -0.86 & 3.39 & 2.37 & 6.59 \\
\hline 1983-1992 & 0.43 & 2.70 & 1.10 & 4.66 \\
\hline 1993-2002 & 1.40 & 2.60 & 0.50 & 2.73 \\
\hline 2003-2011 & -0.74 & 0.73 & -1.38 & 2.01 \\
\hline \multicolumn{5}{|c|}{ The supply of high school or equivalent labor $\left(L_{12, g, t}\right)$ in year $t$ for gender $g$ is constructed as } \\
\hline \multicolumn{5}{|c|}{$L_{12, g, t}=L_{<\mathrm{HS}, g, t}+L_{\mathrm{HSG}, g, t}+0.5 \times L_{\text {Some coll }, g, t}$ where, for example } \\
\hline \multirow{2}{*}{\multicolumn{5}{|c|}{$\begin{array}{l}L_{<\mathrm{HS}, g, t}=Q_{<\mathrm{HS}, g, t} \times N_{<\mathrm{HS}, g, t} \times H_{<\mathrm{HS}, g, t} \text { where } Q \text { is quality, } N \text { is the working age population and } \\
H \text { is hours, and for instance, } N_{<\mathrm{HS}, g, t} \text { is the across cohort (within year) sum of the working age }\end{array}$}} \\
\hline & & & & \\
\hline \multicolumn{5}{|c|}{ population. College or equivalent labor $\left(L_{16, g, t}\right)$ is analogously calculated as } \\
\hline$L_{16, g, t}=L_{\text {Coll grads }, g, t}+L_{>}$ & $\mathrm{oll}, g, t+0.5 \times L_{\mathrm{Sor}}$ & & & \\
\hline
\end{tabular}




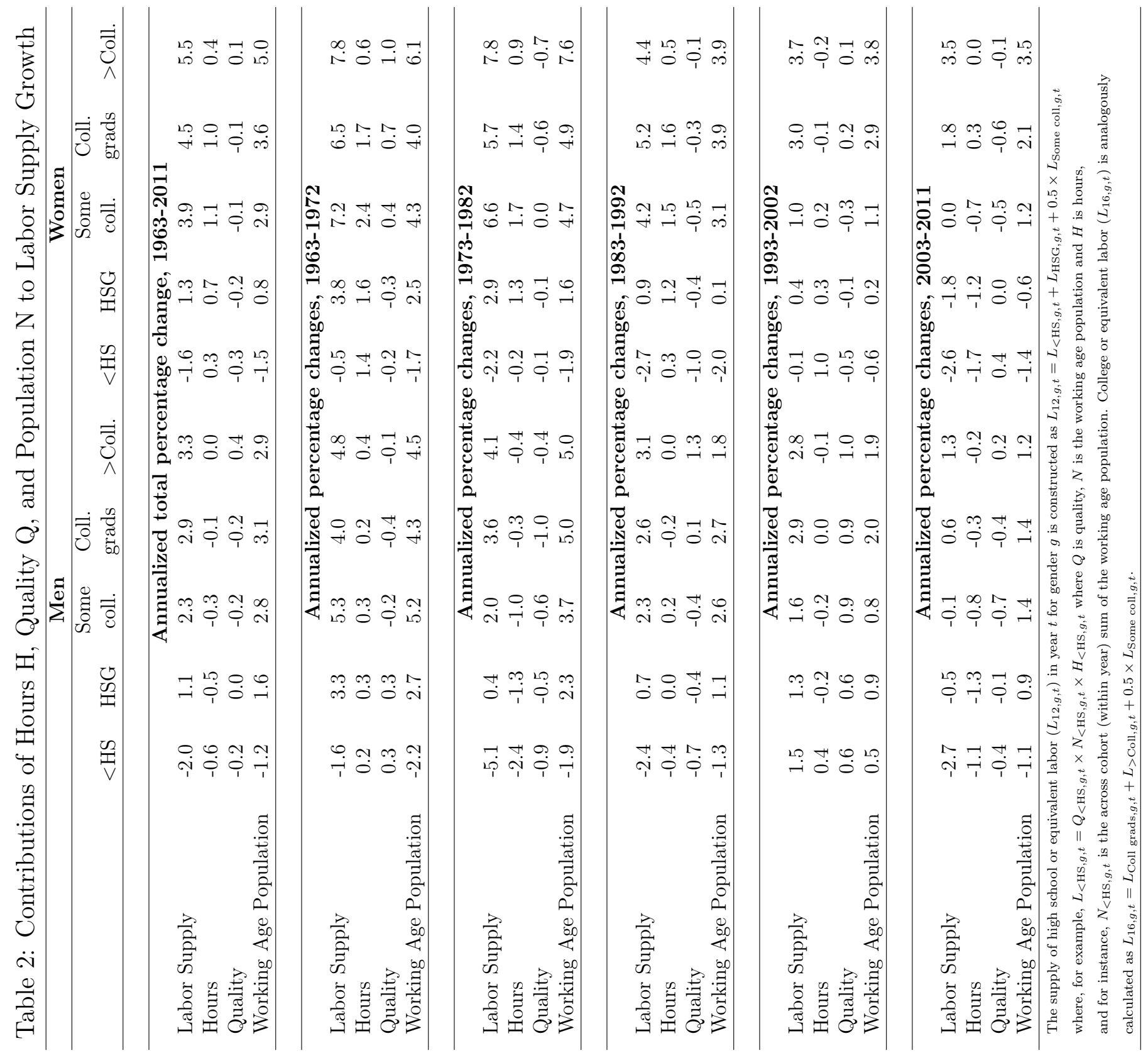


Table 3: 'First Stage' - Endogenous Labor Supply on Instruments

\begin{tabular}{llccc}
\hline & \multicolumn{3}{c}{ Log ratios of labor supply } \\
& $\begin{array}{c}\text { Male/Female } \\
\text { within }\end{array}$ & $\begin{array}{c}\text { Male/Female } \\
\text { within }\end{array}$ & $\begin{array}{c}\text { HS/Coll } \\
\text { within }\end{array}$ & $\begin{array}{c}\text { HS/Coll } \\
\text { within }\end{array}$ \\
& High School & College & Male & Female \\
\hline Year & -0.0269 & -0.0105 & -0.00711 & -0.0176 \\
& {$[0.0010]^{* * *}$} & {$[0.0011]^{* * *}$} & {$[0.0036]^{*}$} & {$[0.0054]^{* * *}$} \\
Labor supply instrument & 2.252 & 1.531 & 1.079 & 0.600 \\
& {$[0.102]^{* * *}$} & {$[0.228]^{* * *}$} & {$[0.195]^{* * *}$} & {$[0.174]^{* * *}$} \\
\hline Observations & 48 & 48 & 48 & 48 \\
R-squared & 0.954 & 0.935 & 0.970 & 0.985 \\
Partial F-stat on instrument & 484.73 & 45.11 & 30.54 & 11.83 \\
Partial R-squared & 0.915 & 0.501 & 0.404 & 0.208 \\
\hline Standard errors in brackets. ${ }^{* * *} \mathrm{p}<0.01,{ }^{* *} \mathrm{p}<0.05, *$ p $<0.1$ & & \\
In each case the labor supply instrument is the log-ratio of the relevant hours-constant \\
labor supply measures. Estimates are from a linear regression with constant term. \\
\hline
\end{tabular}


Table 4: Estimated CES Production function parameters

\begin{tabular}{|c|c|c|c|c|}
\hline \multirow[b]{2}{*}{ Labor Supply: } & \multicolumn{2}{|c|}{ Educ First } & \multicolumn{2}{|c|}{ Gender First } \\
\hline & $\begin{array}{l}\text { Exog } \\
(1)\end{array}$ & $\begin{array}{c}\text { Endog } \\
(2)\end{array}$ & $\begin{array}{c}\text { Exog } \\
(3)\end{array}$ & $\begin{array}{c}\text { Endog } \\
(4)\end{array}$ \\
\hline Nest 1: & Male: & $\mathrm{HS} \& \mathrm{C}$ & \multicolumn{2}{|c|}{ HS: Male \& Female } \\
\hline$b_{0}$ (Intercept) & $\begin{array}{c}0.35 \\
(0.04)\end{array}$ & $\begin{array}{c}0.34 \\
(0.40)\end{array}$ & $\begin{array}{c}0.46 \\
(0.02)\end{array}$ & $\begin{array}{c}0.46 \\
(0.18)\end{array}$ \\
\hline$b_{1}($ time trend $)$ & $\begin{array}{l}-0.009 \\
(0.002)\end{array}$ & $\begin{array}{l}-0.008 \\
(0.017)\end{array}$ & $\begin{array}{c}-0.008 \\
(0.000)\end{array}$ & $\begin{array}{c}-0.008 \\
(0.002)\end{array}$ \\
\hline$\sigma$ & $\begin{array}{c}6.47 \\
(0.06)\end{array}$ & $\begin{array}{c}6.19 \\
(0.48)\end{array}$ & $\begin{array}{c}5.27 \\
(0.03)\end{array}$ & $\begin{array}{c}5.19 \\
(0.26)\end{array}$ \\
\hline Nest 2: & Female: & HS \& C & \multicolumn{2}{|c|}{ C: Male \& Female } \\
\hline$b_{0}$ & $\begin{array}{c}0.61 \\
(0.05)\end{array}$ & $\begin{array}{c}0.64 \\
(0.33)\end{array}$ & $\begin{array}{c}0.97 \\
(0.07)\end{array}$ & $\begin{array}{c}0.99 \\
(0.44)\end{array}$ \\
\hline$b_{1}$ & $\begin{array}{l}-0.017 \\
(0.002)\end{array}$ & $\begin{array}{l}-0.018 \\
(0.013)\end{array}$ & $\begin{array}{l}-0.017 \\
(0.001)\end{array}$ & $\begin{array}{l}-0.018 \\
(0.008)\end{array}$ \\
\hline$\sigma$ & $\begin{array}{c}3.17 \\
(0.05)\end{array}$ & $\begin{array}{c}3.02 \\
(0.31)\end{array}$ & $\begin{array}{c}1.67 \\
(0.08)\end{array}$ & $\begin{array}{c}1.68 \\
(0.44)\end{array}$ \\
\hline Top-Nest: & Male \& & Female & \multicolumn{2}{|c|}{$\mathrm{HS} \& \mathrm{C}$} \\
\hline$b_{0}$ & $\begin{array}{c}0.56 \\
(0.03)\end{array}$ & $\begin{array}{c}0.58 \\
(0.21)\end{array}$ & $\begin{array}{c}0.44 \\
(0.05)\end{array}$ & $\begin{array}{c}0.44 \\
(0.25)\end{array}$ \\
\hline$b_{1}$ & $\begin{array}{l}-0.010 \\
(0.001)\end{array}$ & $\begin{array}{l}-0.011 \\
(0.006)\end{array}$ & $\begin{array}{l}-0.011 \\
(0.002)\end{array}$ & $\begin{array}{l}-0.011 \\
(0.008)\end{array}$ \\
\hline$\sigma$ & $\begin{array}{c}4.06 \\
(0.03)\end{array}$ & $\begin{array}{c}3.88 \\
(0.25)\end{array}$ & $\begin{array}{c}5.53 \\
(0.05)\end{array}$ & $\begin{array}{c}5.53 \\
(0.22)\end{array}$ \\
\hline $\begin{array}{l}\text { Estimation is by } \\
\text { correlation struct } \\
\text { standard errors in }\end{array}$ & $\begin{array}{l}\text { MM accou } \\
\text { e imposed } \\
\text { parenthese }\end{array}$ & $\begin{array}{l}\text { inting for } t \\
\text { on the er } \\
\text { s. }\end{array}$ & Bobust & \\
\hline
\end{tabular}


Table 5: Demand Structure Employed in Projections

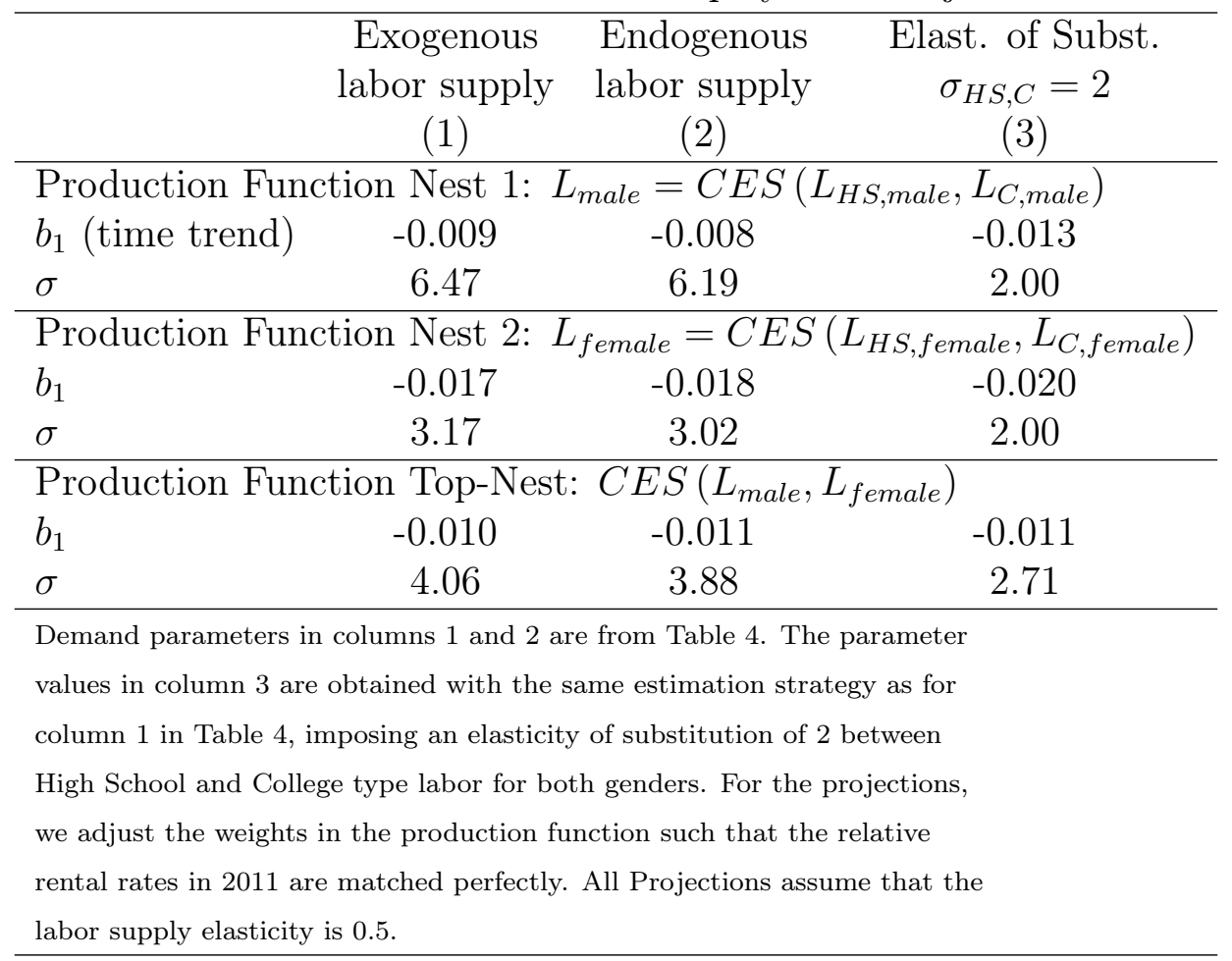

Table 6: Percentage Growth in Rental Rates Relative to College Educated Males 2011-2030

\begin{tabular}{|c|c|c|c|}
\hline & $\begin{array}{l}\text { Exogenous } \\
\text { labor supply } \\
(1)\end{array}$ & $\begin{array}{l}\text { Endogenous } \\
\text { labor supply } \\
(2)\end{array}$ & $\begin{array}{c}\text { Elast. of Subst. } \\
\qquad \sigma_{H S, C}=2 \\
(3)\end{array}$ \\
\hline Female, High School & 6.2 & 11.7 & 16.2 \\
\hline Female, College & 22.3 & 18.1 & 15.1 \\
\hline Male, High School & -13.4 & -10.5 & -8.4 \\
\hline \multicolumn{4}{|c|}{$\begin{array}{l}\text { The table shows the changes in rental rates of human capital for the indicated } \\
\text { groups change relative to college educated males. In column } 1 \text {, we show the changes } \\
\text { implied by the assumption that labor supply is exogenous using the parameter } \\
\text { estimates in column (1) of Table } 5 \text {. Column } 2 \text { uses the parameters estimated in } \\
\text { Table } 5 \text {, col. } 2 \text { and allows for an endogenous labor supply response. Column } 3 \text { uses } \\
\text { the estimates in Table } 5 \text {, col. } 3 \text { and also allows for an endogenous labor supply } \\
\text { response. }\end{array}$} \\
\hline
\end{tabular}


Table 7: 2011-2030 Wage Growth and Education Shares 45 year olds relative to College Educated Males

\begin{tabular}{|c|c|c|c|c|}
\hline & Wage Growth & Rental Rate & Q-Endowment & Share(2011, 2030) \\
\hline & \multicolumn{4}{|c|}{ Male } \\
\hline HS Dropout & $-14.6 \%$ & $-10.5 \%$ & $-4.1 \%$ & $(0.16,0.14)$ \\
\hline High School & $-13.2 \%$ & $-10.5 \%$ & $-2.7 \%$ & $(0.40,0.37)$ \\
\hline Some College & $-7.6 \%$ & $-5.2 \%$ & $-2.4 \%$ & $(0.21,0.23)$ \\
\hline College & - & - & - & $(0.16,0.16)$ \\
\hline \multirow[t]{2}{*}{ More than College } & $5.3 \%$ & - & $5.3 \%$ & $(0.08,0.10)$ \\
\hline & \multicolumn{4}{|c|}{ Female } \\
\hline HS Dropout & $2.0 \%$ & $11.7 \%$ & $-9.7 \%$ & $(0.15,0.11)$ \\
\hline High School & $-0.0 \%$ & $11.7 \%$ & $-12.2 \%$ & $(0.39,0.31)$ \\
\hline Some College & $-0.0 \%$ & $14.9 \%$ & $-15.4 \%$ & $(0.23,0.25)$ \\
\hline College & $2.9 \%$ & $18.1 \%$ & $-15.2 \%$ & $(0.16,0.18)$ \\
\hline More than College & $10.1 \%$ & $18.1 \%$ & $-8.0 \%$ & $(0.07,0.15)$ \\
\hline \multicolumn{5}{|c|}{$\begin{array}{l}\text { The table shows the changes in wages (col. 1), rental rates (col.2), and quality units per } 45 \text { year old } \\
\text { workers (col.3) between } 2011 \text { and } 2030 \text {. These projections are based on the etimates with endogenous labor } \\
\text { supply (see Table } 6 \text {, col.2). Column } 4 \text { shows the population shares of the different education groups among } \\
45 \text { year olds in } 2011 \text { and } 2030 .\end{array}$} \\
\hline
\end{tabular}




\section{Appendix}

\section{A Data sources}

The Current Population Survey (CPS) data used in our analysis is compiled from three sources: March CPS files for 1962-2012 (from David Autor's online data archive http: //econ-www.mit.edu/faculty/dautor/data/autkatkear08 and the NBER for 2008-2012 http://data.nber .org/data/current-population-survey-data.html), May CPS extracts for 1973-78 (from the NBER http://www.nber.org/data/cps_may.html) and the Merged Outgoing Rotation Groups (MORG) data for 1979-2011 (from http: //www . nber .org/morg/ annual/). Compilation of the samples primarily follows Lemieux (2006) and as necessary Autor, Katz and Kearney (2008). Full details of the sample selection and variable construction are detailed in the Online Appendix.

For our predictions we use data on projected population sizes for the years through 2030 by age (in single years), gender and race from the 2008 National Population Projections (NPP) from the Census Bureau (http://www . census.gov/population/projections/data/ national/2008.html, filename NP2008_D1).

\section{B Data construction}

\section{B.1 Rental rates $R_{e, g, t}$}

\section{B.1.1 Flat spot rental rates}

The rental rates for college-equivalent and high school (HS)-equivalent labor are constructed using wage data for respondents aged 50-59 and 46-55 years old, respectively, in the earnings year. For each gender we construct the flat-spot rental rate as the chained annual changes (indexed to 2011) in the age-weighted average wages for college-educated and HS-educated labor. The age weights are year-specific and are based on the size of the full-time equivalent working-age population.

\section{B.1.2 Standard unit rental rates}

The standard unit rental rate series are constructed using age-weighted wages for: (i) college-educated and HS-educated labor aged 20-64 years of age and; (ii) college-educated 
and HS-educated labor aged 50-59 and 46-55 years old, respectivly. The age weights are the share of each age-group in the pooled samples across all CPS years.

\section{B.2 Units of effective human capital (or quality units) $Q_{b, e, g, t}$}

Given $W_{b, e, g . t}=R_{g, e, t} Q_{b, e, g, t}$, we construct the units of effective human capital, $Q_{b, e, g, t}$, for each birth cohort-education-gender-year cell as the ratio of the average wage for each of these cells divided by the relevant rental rate, $R_{e, g, t}$. The flat-spot rental rate for HSequivalent labor, $R_{e=12, g, t}$, is used for the units of effective human capital with less than a high school degree, $Q_{b, e<12, g, t}$, and for the units of effective human capital with a high school degree, $Q_{b, e=12, g, t}$. The flat-spot rental rate for college-equivalent labor, $R_{e=16, g, t}$, is used for the units of effective human capital with a college degree, $Q_{b, e=16, g, t}$, and for the units of effective human capital with more than a college degree, $Q_{b, e>16, g, t}$. For the units of effective human capital with some college, $Q_{b, e=14, g, t}$, we use the average of the rental rates for HS and college-equivalent labor.

\section{B.3 Working age population $N_{b, e, g, t}$}

The size of the working age population, $N_{b, e, g, t}$, is the sum of the population weights for respondents of each birth cohort (restricted to those of working age with positive potential experience).

\section{B.4 Hours supplied $H_{b, e, g, t}$}

Hours supplied, $H_{b, e, g, t}$, are annual hours (weeks worked times weekly hours). When we instrument for hours, we again use annual hours in constructing average hours for a given age across cohorts, $\bar{H}_{e, g, a}$.

\section{B.5 Labor supplied}

\section{B.5.1 Effective units of labor supplied by HS- and college-equivalents}

For use in the demand system estimation we require measures of the effective units of labor supplied by HS- and college-equivalents (by gender). We form our measure of effective units of labor supplied by HS-equivalents as the sum (across cohorts and within year) of the product of the relevant units of effective human capital, $Q_{b, e=12, g, t}$, and a measure of the

full-time equivalent (FTE) working age population for HS-equivalent workers, $\widetilde{N H}_{b, e=12, g, t}$. 
Similarly, the effective units of labor supplied by college-equivalents is the product of the relevant units of effective human capital, $Q_{b, e=16, g, t}$, and a measure of the full-time equivalent working age population for college-equivalent workers, $\widetilde{N H}_{b, e=16, g, t}$.

To construct the measures $\widetilde{N H}_{b, e, g, t}$ we first define three 'exchange rates' based on the ratios of average wages within birth cohort and across years for each education, $w c o h_{b, e, g}$. These

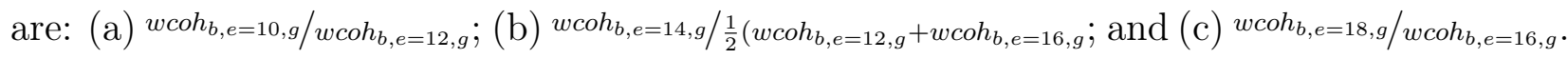
For the FTE working age population of HS-equivalent workers, $\widetilde{N H}_{b, e=12, g, t}$, we then sum the FTE working-age population with: (i) exactly a HS education; (ii) less than a HS education weighted by exchange rate (a) above; and (iii) half of the FTE working-age population with some college weighted by exchange rate (b) above. The measure $\widetilde{N H}_{b, e=16, g, t}$ is analogously defined as the sum of the FTE working-age population with: (i) exactly a college education; (ii) more than a college education weighted by exchange rate (c) above; and (iii) half of the FTE working-age population with some college weighted by exchange rate (b) above.

The assumptions underlying this approach are: (1) labor is perfectly substitutable across age within education; (2) labor is perfectly substitutable across schooling. The second assumption implies that the prices of these labor inputs are fixed ratios and this allows us to attribute the human capital of "high school drop-outs" and those with "some college" to the HS-equivalent labor group, and to attribute the human capital of "post-graduate" and "some college" individuals to the college-equivalent labor group.

\section{B.5.2 Labor supplied separately by each education}

For use in Sections II, V and VI we form a measure of labor supplied in education $(e=10,12,14,16,18)$, gender $(g)$ and year $(t)$ as the across birth cohort $(b)$ average of $L_{b, e, g, t}=$ $Q_{b, e, g, t} * H_{b, e, g, t} * N_{b, e, g, t}$. That is, we take the units of effective labor multiplied by the hours of labor supplied multiplied by the size of the working age population (with positive potential experience). For Table 1, we also construct measures of the total labor supplied, for HS- and college-equivalent labor using the across birth cohort $(b)$ average of: $X_{b, \text { Coll,g,t }}=X_{b, 16, g, t}+$ $X_{b, 18, g, t}+\frac{1}{2} X_{b, 14, g, t}$ and $X_{b, H S, g, t}=X_{b, 12, g, t}+X_{b, 10, g, t}+\frac{1}{2} X_{b, 14, g, t}$ where $X=\{L, Q, H, N\}$. 


\section{Online Appendix to Edwards and Lange (2013) - Not for publication}

November 25, 2013

\section{Detailed description of the data}

\subsection{Data Sources}

We use data from the Current Population Surveys (CPS) for our analysis. The data is compiled from three CPS sources: March CPS files for 1962-1972 ${ }^{1}$, the May CPS extracts for 1973-78 and the Merged Outgoing Rotation Groups (MORG) data for 1979-2011. When annual hours data are needed, we take these from the March CPS files for 1962-2012.

This data was sourced from:

- the NBER CPS web pages for the May and MORG data (http://www.nber.org/data/cps_may.html, http://www . nber.org/morg/annual/).

- David Autor's online data archive for the March data through 2007 (http://econ-www.mit.edu/ faculty/dautor/data/autkatkear08). We also consulted the cleaning programs available there. In addition, we used more recent years from the March CPS files to check the robustness of our findings. ${ }^{2}$

- the NBER CPS web pages for the March data from 2008-2012

(http://data.nber.org/data/current-population-survey-data.html).

Compilation of the samples primarily follows Lemieux (2006). However, for the March sample where additional steps were required to clean and process the data, we also referred to Autor et al. (2008). Sample selection is detailed in Section 1.2. For a detailed description of the variable construction see Sections 1 and 1.5 below.

For forecasting, we also collected data from the Census population forecasts. Details of the data collated and methodology used for the predictions are provided in section 2.

\footnotetext{
${ }^{1} 1963$ data is not used because data on education completed is missing

${ }^{2} \mathrm{~A}$ note on the timing of the March files: the survey year data on work and wages refers to the prior year - thus variables are adjusted to refer to that earnings year - for example the year is the Survey Year minus 1, experience is age - education - 7 (to correct for the age being age in survey year rather than age in the year of work) and so forth.
} 


\subsection{Sample Selection}

\subsubsection{Rental rates and wages: $Q_{b, e, g, t}, R_{e, g, t}, W_{b, e, g . t}$}

To measure rental rates and wages we choose those respondents who are between the ages of 20-64 years in the earnings year and who have positive potential experience (calculated as age - years of completed education - 6). We use (largely following both Lemieux (2006) and Autor et al. (2008)) except where indicated otherwise) those respondents who are wage and salary earners (i.e. we exclude the self employed, those who have never worked and those who work with no pay), those with non-missing wages, those with non-allocated wages and those with wages greater than $\$ 1$ and less than $\$ 100$ in real terms. To minimize potential division bias arising from our construction of wages as earnings divided by hours we exclude those respondents who worked fewer than 10 hours/week and in addition we exclude those who worked fewer than 40 weeks in the year for the March data. In addition, for March data (following Autor et al. (2008)) we also drop those not working between 1 and 52 weeks in the earnings year, those in the Armed forces and those who were students in the earning year.

\subsubsection{Hours: $H_{b, e, g, t}$}

To measure annual hours worked we choose those respondents who are between the ages of 20-64 years in the earnings year and who have positive potential experience (calculated as age - years of completed education - 6). We use annual hours from the March CPS data and include those with zero or positive work hours.

\subsubsection{Populations: $N_{b, e, g, t}$}

To measure the population size we choose those respondents who are between the ages of 20-64 years in the earnings year and who have positive potential experience (calculated as age - years of completed education $-6)$.

\subsection{Data construction}

\subsubsection{Rental rates $R_{e, g, t}$}

Flat-spot rental rates Following Heckman et al. (1998) we assume that at older ages, changes in wages are due solely to changes in skill prices (assuming no depreciation of skills). At these ages, the flat-spot, we assume that skills are constant and thus variation in wages are - on average - due to changes in skill prices. We also assume that there two type of human capital: high school and college. Following Bowlus and Robinson (2012) we set the flat spot at ages 46-55 years for those with a high school degree and at ages 50-59 years for those with a high school degree and use observations at these ages to generate a price series for the human capital or skills of high school graduates and college graduates.

To construct these rental rates we use wage data for respondents in the earnings year. We construct age-weighted average wages by year for college-educated and high-school (HS) educated labor. We do this for each gender ${ }^{3}$ using the full-time equivalent working-age population. The flat-spot skill price series is the chained annual changes in these age-weighted average wages, indexed to 2011.

\footnotetext{
${ }^{3}$ We consider men and women of any race and for robustness we confirm the qualitative results for whites only.
} 
Standard unit rental rates For robustness, we also constructed alternative rental rate series that are constructed following the methods used by Katz and Murphy (1992) and later Autor et al. (2008). These rental rate series are obtained by attributing changes in average wages conditional on educational attainment to changes in skill prices. The implicit assumption is that the average human capital conditional on demographics is constant over time. To obtain average wages that control for shifts in the demographic compositoin over time, the data is weighted. We construct two wage series based on weights that adjust to a constant age distribution. The age weights are the given by the share of each age-group in the pooled samples across all CPS years. We construct two series based on these weights:

1. A series of rental rates based on mean wages for individuals aged 20-64.

2. A series of rental rates based on mean wages for individuals at the flat spot ages (46-55 and 50-59 years of age for high school and college educated workers).

\subsubsection{Units of effective human capital (or quality units) $Q_{b, e, g, t}$}

Given $W_{b, e, g . t}=R_{g, e, t} Q_{b, e, g, t}$, we construct the units of effective human capital, $Q_{b, e, g, t}$, for each birth cohort-education-gender-year cell as the ratio of the average wage for each of these cells divided by the relevant rental rate, $R_{e, g, t}$. The flat-spot rental rate for HS-equivalent labor, $R_{e=12, g, t}$, is used for the units of effective human capital with less than a high school degree, $Q_{b, e<12, g, t}$, and for the units of effective human capital with a high school degree, $Q_{b, e=12, g, t}$. The flat-spot rental rate for college-equivalent labor, $R_{e=16, g, t}$, is used for the units of effective human capital with a college degree, $Q_{b, e=16, g, t}$, and for the units of effective human capital with more than a college degree, $Q_{b, e>16, g, t}$. For for the units of effective human capital with some college, $Q_{b, e=14, g, t}$, we use the average of the rental rates for HS and college-equivalent labor.

\subsubsection{Working age population $N_{b, e, g, t}$}

The size of the working age population (with positive potential experience), $N_{b, e, g, t}$, is the sum of the population weights for respondents of each birth cohort (restricted to those of working age with positive potential experience).

\subsubsection{Hours supplied $H_{b, e, g, t}$}

Hours supplied, $H_{b, e, g, t}$, are annual hours (weeks worked times weekly hours). When we instrument for hours, we again use annual hours in constructing average hours for a given age across cohorts, $\bar{H}_{e, g, a}$.

\subsubsection{Labor supplied}

Effective units of labor supplied by HS- and college-equivalents For use in the demand system estimation we require measures of the effective units of labor supplied by HS- and college-equivalents (by gender and year). To construct these, we convert units of labor (and it's embodied skill) supplied by those with less than HS, some college or any post-graduate education into units of HS- or college-equivalents. To do this, we:

1. Take the average wage by birth cohort for each education and construct three 'exchange rates' to use for the conversion of the units of skill. These exchange rates are: (i) the ratio of the within-cohort 
average wage for those with less than a HS education to the within-cohort average wage for those with a HS education; (ii) the ratio of the within-cohort average wage for those with less than a HS education to the average of the cohort-average wage for those with a HS education and the within-cohort average for those with a college education; (iii) the ratio of the within-cohort average wage for those with any post-graduate education to the within-cohort average wage for those with a college education. These exchange rates are constant weights across time, but they vary by birth cohort.

2. For each year, construct the quantity of college-equivalent labor as the sum of: (i) the full-time equivalent working-age population with exactly a college education; (ii) half of the full-time equivalent working-age population with some college weighted by college-equivalent units of skill supplied by this group as constructed in (1); (iii) the full-time equivalent working-age population with any postgraduate education weighted by college-equivalent units of skill supplied by this group as constructed in (1).

3. For each year, construct the quantity of HS-equivalent labor as the sum of: (i) the full-time equivalent working-age population with exactly a HS education; (ii) half of the full-time equivalent workingage population with some college weighted by HS-equivalent units of skill supplied by this group as constructed in (1); (iii) the full-time equivalent working-age population with less than a HS education weighted by HS-equivalent units of skill supplied by this group as constructed in (1).

4. Take the two quantity series from steps (2) and (3) and construct the effective units of labor supplied by HS- and college-equivalent workers by year. To do so, in each year-cohort, we: (i) multiply the quantity of college-equivalent labor by the units of effective human capital for college-equivalents, $Q_{b, e=16, g, t}$, as defined in Section 1.3.2; and analogously (ii) multiply the quantity of HS-equivalent labor by the units of effective human capital for HS-equivalents. For each of these two series, we then sum the quantity of quality units across birth cohorts within each year.

The assumptions underlying this approach are as follows:

1. Within an education class (less than HS, HS, some college, college, or any post-gradute) labor is assumed perfectly substitutable across age.

2. Substitutability Across Schooling Groups: We assume that certain types of human capital are perfect substitutes. This implies that the prices of these inputs are fixed ratios. We use this assumption when we attribute the human capital of "high school drop-outs" and those with "some college" to the HS-equivalent education or unskilled labor group, and when we attribute the human capital of "post-graduate" and "some college" individuals to the skilled or college labor group.

Labor supplied separately by each education For use in the labor supply decomposition and projections we form a measure of labor supplied in education $(e=10,12,14,16,18)$, gender $(g)$ and year $(t)$ as the across birth cohort $(b)$ average of $L_{b, e, g, t}=Q_{b, e, g, t} * H_{b, e, g, t} * N_{b, e, g, t}$. That is, we take the units of effective labor multiplied by the hours of labor supplied multiplied by the size of the working age population (with positive potential experience). For Table 1, we also construct measures of the total labor supplied, for HS- and college-equivalent labor using the across birth cohort $(b)$ average of: $X_{b, C o l l, g, t}=$ $X_{b, 16, g, t}+X_{b, 18, g, t}+\frac{1}{2} X_{b, 14, g, t}$ and $X_{b, H S, g, t}=X_{b, 12, g, t}+X_{b, 10, g, t}+\frac{1}{2} X_{b, 14, g, t}$ where $X=\{L, Q, H, N\}$. 


\subsection{Variable Definitions}

The key variables constructed are described briefly in Table 1. Further details regarding variable construction can be found in Section 1.5.

\begin{tabular}{|c|c|}
\hline Variable & Definition \\
\hline Year & $\begin{array}{l}\text { Earnings year: } \\
\text { survey year for May and MORG data, survey year-1 for March data }\end{array}$ \\
\hline Gender & Male $=1$, Female $=0$ \\
\hline Age & in years \\
\hline Cohort & year - age \\
\hline Race & White $=1$, Any non-white $=2$ \\
\hline \multirow[t]{5}{*}{ Education } & Less than High School degree (or 11 or fewer yrs completed) \\
\hline & High School Degree or diploma (or 12 yrs completed) \\
\hline & Some college, or Technical college (or 13-15 yrs completed) \\
\hline & College Graduate (or 16 yrs completed) \\
\hline & Any Post graduate education (or 17 or more yrs completed) \\
\hline Experience (potential) & Age - education - 6 \\
\hline Log Wage & the log of the real hourly wage $(1979=100)$ in the earnings year \\
\hline Frequency weight & CPS weight \\
\hline \multirow[t]{2}{*}{ FTE frequency weight } & MORG data: CPS weight $\times$ weekly hours $/ 40$ \\
\hline & $\begin{array}{l}\text { March data: CPS weight } \times \text { weekly hours } / 35 \times \text { weeks worked } 40 \\
(\text { FTE is full-time equivalent) }\end{array}$ \\
\hline
\end{tabular}

\subsection{Notes on the Key Variables}

\subsubsection{Wages}

MORG data: ${ }^{4}$ Wages are reported hourly earnings or, where that is missing, wages are constructed from weekly earnings divided by usual hours.

March data: Hourly earnings is annual earnings divided by weeks worked and usual hours in the earnings year. The March survey asks respondents about earnings and hours in the previous year. Also note, following Autor et al. (2008), that the original variable "hours" from the current survey year were topcoded at 98 or 99 depending on the year. So we redefine the topcode to be 98 for all years.

Deflating wages: We deflate wages using the CPI. The CPI series used is CPI-U, Series ID CUSR0000SA0, Seasonally adjusted, US city, All items. We re-base to 1979 (average) $=100 .^{5}$

Top coding: Top-coded wages and earnings were multiplied by 1.4 following Lemieux (2006). For the MORG data we use the top-codes described by Lemieux and for the March data we follow Autor et al. (2008). In addition, for the March data we also follow Autor et al. (2008) and replace earnings top codes with top code*1.4 and then wages with top coded earnings*1.4/1400 (where $1400=40$ weeks times 35 hours

\footnotetext{
${ }^{4}$ If not mentioned specifically, the May 1973-1978 data is treated analogously to the MORG 1979-2006 data.

${ }^{5}$ Lemieux references Card and DiNardo (2002) who use CPI-U-X1 which is a research series that has a rental equivalence correction. This series was not available to cover our longer sample period.
} 
per week, that is, full time equivalent) if the wage $=$ earnings $/($ wks $\times$ hours $)$ is greater than (top coded earnings*1.4/1400).

Top coding is as follows:

May 1973-78: Wages top coded at $\$ 99.99$ and earnings at $\$ 999$.

MORG: Wages top coded at $\$ 99.99^{6}$ and earnings at $\$ 999$ (between 1979-1988), \$1923 (between 19891997) and $\$ 2884$ (between 1998 and 2011).

March data - Earnings are top-coded in the survey data at $\$ 90000$ (for 1962 and 1964), $\$ 99900$ (between 1965-1967), $\$ 50000$ (between 1968-1981), $\$ 75000$ (between 1982-1984) and $\$ 99999$ (between 1985-1987). For 1988 onwards earnings is the sum of two variables - primary and secondary earnings. Primary earnings are top-coded at $\$ 99999$ (1988-1995), \$150000 (between 1996-2002), \$200000 (between 2003-2010) and $\$ 250000$ from 2011. Secondary earnings were top coded at $\$ 9999$ (in 1988, 1990, 1992-1995), \$95000 (in 1989), $\$ 90000$ (in 1991), $\$ 25000$ (between 1996-2002), \$35000 (between 2003-2010) and $\$ 47000$ from 2011.

Allocated wages: Where possible we have used non-allocated wages and have excluded observations with only allocated wages.

May 1973-78: there are no allocated wages

MORG: We follow Autor et al. (2008) and use the available flags from the CPS for allocated wages. ${ }^{7}$ As a result we exclude the data for 1994 and Jan-July of 1995 because for this period there are no allocation flags and thus no way to exclude those with allocated wages. In addition, for 1989-1993 the allocation flags have been found to be incorrect and they fail to identify most workers with missing wages. So here also we follow Lemieux (2006), Hirsch and Schumacher (2004) and Autor et al. (2008) and exclude those observations with missing unedited weekly earnings and we do not used the edited weekly earnings data).

March: We follow Autor et al. (2008) and exclude allocated earnings data (after the 1965 earnings year) using a family earnings allocation flag and from 1975 (earnings year) using individual earnings allocation flags. ${ }^{8}$

Trimming: For all data samples we trim wages below at real wage of $\$ 1$ and above at real wage of $\$ 100$ (in 1979 dollars). This follows Lemieux (2006).

Imputing hours prior to $\mathbf{1 9 7 5}$ - March data: Note that observations on hours worked per week last year are not available prior to 1975 in the March CPS data and weeks worked is reported in brackets. As a result, we follow Autor et al. (2008) (code available and sourced from David Autor's website noted above) and perform an 'imputation' of hours and weeks in order to generate a wage. For weeks worked, we take the mean weeks worked last year by race and sex for the years 1976-78 for each bracket and use those means for the years 1962-75. For hours worked last year, we take the estimated relationship between hours last week

\footnotetext{
${ }^{6}$ There are a few observations on wages of 99.00 - we replace these with $\$ 99.99 \times 1.4$

${ }^{7}$ Allocated wages, weekly earnings or hours are identified by variables I25a, I25b, I25c, I25d as per the documentation file available online: cpsx.pdf. Specifically, for 1979 to 1988 the coding scheme is: Not allocated 0, allocated 1 . For 1989 to 1993 the coding scheme is: $4=$ allocated. We drop all for which I25a through I25d are $\geq 4$. For 1994 and beyond I25a and I25b range from 0 to 53 . Values over three signify allocated data. We drop $\geq 4$. For 1996 on the coding scheme for I25c and I25d is: Not allocated 0 , allocated 1 .

${ }^{8}$ The allocation flag variable used is aincwag.
} 
and last year in the 1976-78 data to predict hours worked last year for 1962-75 using the available data on hours worked last week. ${ }^{9}$

\subsubsection{Weights}

We use full-time equivalent frequency weights in our analysis. These are computed as the CPS weight multiplied by hours of work and divided by full-time hours. Thus, for the May and MORG CPS data we take the CPS weight $\times$ hours per week / 40 hours and for the March CPS data we take the CPS weight $\times$ hours per week / 35 hours $\times$ weeks per year / 40 weeks. In choosing these weightings we follow Lemieux (2006) and Autor et al. (2008) respectively.

Additional adjustments: We find that in both the MORG and the March data other small adjustments to the weights are necessary to ensure a smooth evolution of the implied population size in aggregate and after excluding those without valid wage data.

MORG: We find that the CPS weights for the years 1979-1993 and 1996-2011 generate a population that is too large by a factor of three. To correct for this we take the survey weights and divide by 3. For 1995, this adjustment is unnecessary as we only have 4 months of data (the other months are not available because there are no allocation flags present to exclude edited wages).

When we look to analyze average wages and skill prices, we find that the weights imply a sharp drop in the US population for the years 1996-2011. This drop arises because of the decision to exclude allocated wages which become more pervasive after 1994 following a change in the survey methodology and more specifically in the earnings questions. At that time there is an increase in the number of observations with allocated wages and hours. Thus after dividing the weights for the post 1995 years by 3 (for the same reason as above) we then mutiplied the weights used on the wage data by a factor of around 1.1248 to correct for this discontinuity.

March: Weights are adjusted in 1966 (1965 earnings) by dividing by two, as it appears to be a doublesample. For the years from 1988 inclusive, we find that the weights imply a sharp increase in the US population. This corresponds to the earnings year for which the CPS begins to collect wage and salary information separately. As a result, at this time there is a fall in the number of observations with allocated wage data likely due to the fact that there it is possible to get wage or earnings data or both from this year onwards and so fewer observations had to be excluded. To correct for this, we divided the weights used on the wage data by 1.21 .

\subsubsection{Education}

Prior to 1991, for the May (1973-78), MORG and March data, years of education is constructed using years of schooling attended and is then corrected for years completed. From 1992 the March and MORG CPS data switched to coding educational achievement using degrees rather than years. The education sub-groups we use are thus:

\footnotetext{
${ }^{9}$ The full regression takes hours last year and regresses it on hours last week, an indicator for zero hours last week, an indicator for whether or not the respondent usually worked 35+ hours last year (fulltime), an indicator for whether hours last week were zero because the respondent was not in the labor force NILF, an interaction of hours and the fulltime indicator and an interaction of the zero hours last week indicator and the fulltime indicator.
} 
Less than High School: Those with fewer than 12 years of schooling completed or, from 1992, those who did not graduate from high school and have with no diploma.

High School Grad: Those with 12 years of completed schooling and, from 1992, High School Graduates and those with a Diploma or GED.

Some College: Those with more than 12 years and less than 16 years of completed schooling, and from 1992 those with some College but no degree or with an Associate Degree.

College Graduate: Those with 16 years of completed education and from 1992 those with a Bachelor's degree.

Any postgraduate education: Those with more than 16 years of completed education and from 1992 those with a masters, professional or graduate degree. Due to the change in form of the CPS education questions from 1992, in both our March and MORG CPS samples there is a clear decline in the share of the population in less than high school group, a small decline in the high school graduate group, a clear increase in the share with some college education, a small increase in those with a college degree and a clear decrease in the share with post graduate education. That is, for example, some individuals that were previously declared as not having finished high school are now being declared as having graduated from high school. Therefore, we are mis-measuring the changes in quantities. To ensure a smooth evolution of the shares of the population in each education category we have rescaled the CPS population weights to remove this kink. Specifically, for the 1993 survey year we re-scale the population weights so that the quantities be equal to the 1992 observed value and from that point forward the re-scaling ensures that the population shares in each schooling group grow or shrink at their observed growth rates.

\section{Data and methodology for predictions}

\subsection{Population projections - Census data}

We sourced data on projected population sizes for the years through 2050 by age (in single years), gender and race from the 2008 National Population Projections (NPP) compiled by the Census Bureau (http:// www. census.gov/population/projections/data/national/2008.html, filename NP2008_D1). From this data we get population growth rates by age and demographic group.

From the CPS data, there is sampling variation for each birth cohort in each year. To smooth this out when making our population projections, we use a simple regression prediction for the population size for each age and demographic group in 2011. The regression is of the 2011 population size by age and demographic group on dummies for the demographic groups interacted with a quartic in age. Note that the population here includes all respondents between the ages of 20-64 years, with any potential experience (positive, 0 or negative).

We use this predicted population size in 2011 a to use as a baseline and then grow that population using the age-specfic growth rates from the Census NPP data. 
The final data for populations used in our projections is then CPS data through to 2011 and the projections using the Census growth rates from 2012-2030.

\subsection{Quality or skill projections}

We use our measure of labor quality or skill, $Q_{b, e, g, t}$, as described in section 1.3.2. We project skill for 2011-2030 using predictions from a flexible linear regression of $Q_{b, e, g, t}$ on the full set of interactions between dummies for birth cohorts prior to 1960, education and demographic group, birth cohort (from 1960-1986) interacted with both education and demographic dummies and the full set of interactions between dummies for age, education and demographic group.

\subsection{Education projections}

To form projections of the share of the population with each level of schooling we use the population sample of all respondents between the ages of 20-64 years, with any potential experience. Then for each cohort and demographic group, we:

1. measure the share that has not completed high school using those aged 22-25 years

2. measure the share that has completed high school as 1 minus the share that has not completed high school using those aged 22-25 years

3. find the probability of getting more than a high school education using those aged 24-28 years, conditional on at least completing high school

4. find the probability of getting more than some college (i.e. more than an associates degree or completing only some of a 4-year college degree) using those ages 26-30 years, conditional on getting more than a high school degree

5. find the probability of undertaking any graduate study using those aged 30-34 years conditional on getting a college degree.

We then use the post-1960 cohorts (i.e. those that made education choices roughly at or after the beginning of the turnaround in the returns to education) to project the education trends. To make the projections we regress each of the measures (2)-(5) from above on birth cohort and form a simple linear prediction.

\section{References}

Autor, David H, Lawrence F Katz, and Melissa S Kearney, "Trends in US wage inequality: Revising the revisionists," The Review of Economics and Statistics, 2008, 90 (2), 300-323.

Heckman, J, L Lochner, and C Taber, "Explaining Rising Wage Inequality: Explorations with a Dynamic General Equilibrium Model of Labor Earnings with Heterogeneous Agents," Review of Economic Dynamics, January 1998, pp. 1-58.

Hirsch, Barry $\mathbf{T}$ and Edward $\mathbf{J}$ Schumacher, "Match bias in wage gap estimates due to earnings imputation," Journal of Labor Economics, 2004, 22 (3), 689-722. 
Katz, Lawrence F and Kevin M Murphy, "Changes in relative wages, 1963-1987: supply and demand factors," The Quarterly Journal of Economics, 1992, 107 (1), 35-78.

Lemieux, Thomas, "Increasing residual wage inequality: Composition effects, noisy data, or rising demand for skill?," American Economic Review, 2006, pp. 461-498. 